LA-14316

Approved for public release;

distribution is unlimited.

Synthesis and Characterization of

Nonbanded U-Nb Plate Material 
Edited by Mable Amador, Group IRM-CAS

Photocomposition by E. Katherine Valdez, Group IRM-CAS

Los Alamos National Laboratory, an Affirmative Action/ Equal Opportunity Employer, is operated by Los Alamos National Security, LLC, for the National Nuclear Security Administration of the U.S. Department of Energy under contract DE-AC52-06NA25396.

\section{NSS NNSA \\ National Nuclear Security Administration}

This report was prepared as an account of work sponsored by an agency of the U.S. Government. Neither Los Alamos National Security, LLC, the U.S. Government nor any agency thereof, nor any of their employees make any warranty, express or implied, or assume any legal liability or responsibility for the accuracy, completeness, or usefulness of any information, apparatus, product, or process disclosed, or represent that its use would not infringe privately owned rights. Reference herein to any specific commercial product, process, or service by trade name, trademark, manufacturer, or otherwise does not necessarily constitute or imply its endorsement, recommendation, or favoring by Los Alamos National Security, LLC, the U.S. Government, or any agency thereof. The views and opinions of authors expressed herein do not necessarily state or reflect those of Los Alamos National Security, LLC, the U.S. Government, or any agency thereof. Los Alamos National Laboratory strongly supports academic freedom and a researcher's right to publish; as an institution, however, the Laboratory does not endorse the viewpoint of a publication or guarantee its technical correctness. 
LA-14316

Issued: January 2007

\section{Synthesis and Characterization of}

\section{Nonbanded U-Nb Plate Material}

R. E. Hackenberg, R. M. Aikin, Jr., J. A. Balog, B. L. Bingham,

R. Casey, A. Casteel, I. Cordova, R. Forsyth, F. G. Garcia, D. Guidry,

D. L. Hammon, W. L. Hults, D. R. Korzekwa, A. M. Kelly, M. W. Koby,

K. A. Lao, J. C. Lashley, M. F. Lopez, R. McCabe, D. E. Nye,

P. A. Papin, S. W. Quintana, J. L. Smith, D. F. Teter, D. J. Thoma,

T. Tucker, P. K. Tubesing, R. R. Trujillo, C. J. Vigil, and H. M. Volz 



\section{TABLE OF CONTENTS}

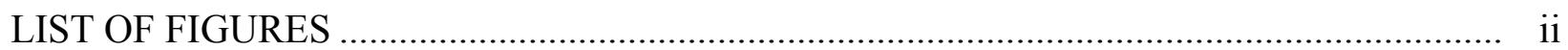

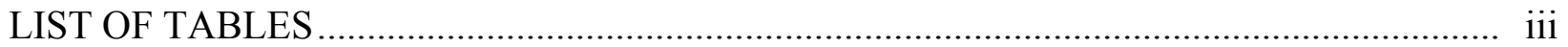

LIST OF ACRONYMS AND SYMBOLS...................................................................... iv

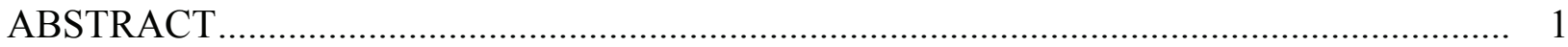

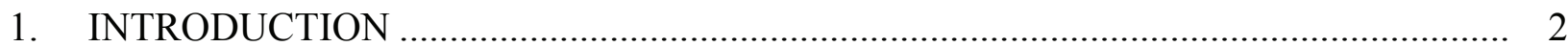

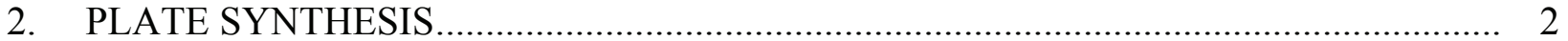

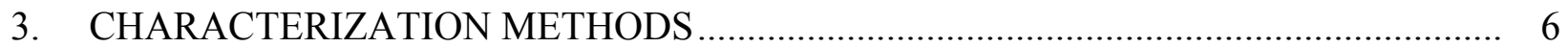

3.1. Metallography and Microprobe ………………................................................... 6

3.2. Chemical Analysis ....................................................................................... 8

3.3. Other Characterization .................................................................................. 10

4. CHARACTERIZATION AFTER CASTING AND ROLLING ....................................... 11

5. CHARACTERIZATION AFTER HOMOGENIZATION ................................................ 14

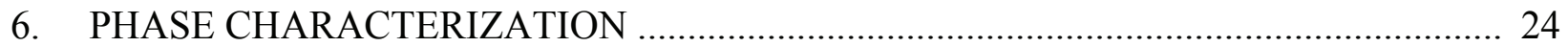

7. PROPERTY CHARACTERIZATION ........................................................................... 29

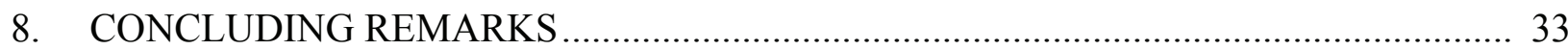

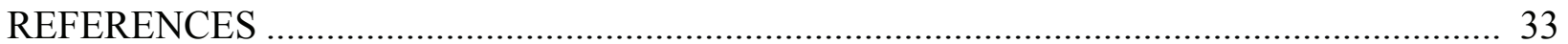




\section{LIST OF FIGURES}

Figure 1. Graphite mold design used to cast 0.56-in.-thick semioctagonal U-Nb plates.

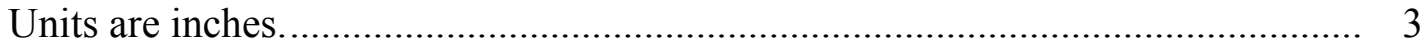

Figure 2. Sketch of plate carve-up................................................................... 4

Figure 3. Change in appearance of X-ray diffraction data with electrochemical etch time for as-quenched $03 \mathrm{~K}-422$ (U-7.7Nb actual). ............................................... 10

Figure 4. Cylindrically-symmetric tensile specimen geometry used in this study............... 12

Figure 5. As-cast microstructure, taken from the location 1, center plane of 03K-422........ 13

Figure 6. As-cast microstructure, taken from the location 1, center plane of 03K-424........ 14

Figure 7. As-cast microprobe traces from $03 \mathrm{~K}-422$ at coarse $(\mathrm{a}-\mathrm{d})$ and fine $(\mathrm{e}-\mathrm{f})$ scales..... 15

Figure 8. Post-rolling optical micrographs of 03K-422 (a, b) and 03K-424 (c, d), cross-section plane of polish........................................................................... 16

Figure 9. Post-rolling microprobe traces of 03K-422 (a, b) and 03K-424 (c, d)................ 17

Figure 10. Optical micrographs showing $03 \mathrm{~K}-422$ after $1,000^{\circ} \mathrm{C}-6$-hour homogenization and water quench. ................................................................................. 18

Figure 11. Optical micrographs showing $03 \mathrm{~K}-425$ after $1,000^{\circ} \mathrm{C}-6$-hour homogenization and water quench. ................................................................................... 19

Figure 12. As-homogenized microprobe traces of 03K-422 (a, b) and 03K-425 (c, d) at coarse $(a, c)$ and fine $(b, d)$ scales. ............................................................ 20

Figure 13. Global microprobe trace across the entire cross-section of the four as-homogenized plates. ...................................................................... 21

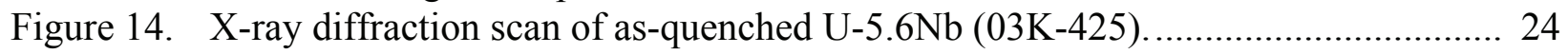

Figure 15. X-ray diffraction scan of two different samples of

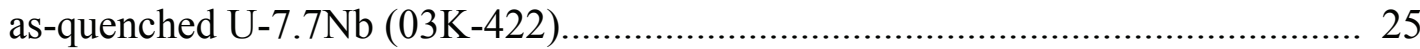

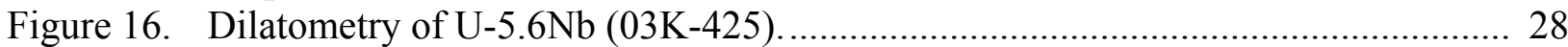

Figure 17. Electrical resistivity during subambient cooling of $03 \mathrm{~K}-422$ (U-7.7Nb actual)..... 29

Figure 18. Tensile stress-strain curves for nonbanded $\mathrm{U}-5.6 \mathrm{Nb}(03 \mathrm{~K}-425,5$ replicates) and nonbanded $\mathrm{U}-7.7 \mathrm{Nb}(03 \mathrm{~K}-422,7$ replicates $)$.

Figure 19. SEM fractographs from a subset of Fig. 18 as-quenched $\mathrm{U}-\mathrm{Nb}$ tensile specimens. 


\section{LIST OF TABLES}

Table 1. Plate characteristics.

Table 2. MST-6 Characterization Team job numbers and techniques employed for the characterization of the plates in various conditions. HV = microhardness, $\mathrm{LOM}=$ light optical microscopy, EPMA = electron microprobe, $\mathrm{TEM}=$ transmission electron microscopy, $\mathrm{CA}=$ chemical analysis.

Table 3. Material Pedigree identification numbers for characterization of the plates in various conditions as listed in the Los Alamos Materials Information System (LAMIS) Metals and Ceramics Granta database.

Table 4. Chemical analysis results from the four U-Nb plates, in weight parts per million (wppm).

Table 5. Refined lattice parameters and derived parameters for as-quenched U-5.6Nb $(03 \mathrm{~K}-425)$ and $\mathrm{U}-7.7 \mathrm{Nb}(03 \mathrm{~K}-422)$ alloys.

Table 6. Mechanical properties of U-Nb alloys. Vickers microhardness (HV) was measured with a 500-gram load. 


\section{LIST OF ACRONYMS AND SYMBOLS}

\begin{tabular}{|c|c|}
\hline$\% \mathrm{RA}$ & $\%$ reduction in area \\
\hline$\alpha^{\prime \prime}$ & monoclinic phase found in alloyed uranium \\
\hline$\gamma$ & body-centered cubic phase found in pure and alloyed uranium \\
\hline$\gamma^{\circ}$ & tetragonal phase found in uranium alloys, a distorted form of $\gamma$ \\
\hline$\theta$ & incident angle of beam to specimen in an X-ray diffractometer \\
\hline $03 \mathrm{~K}-422$ & LANL/MST- 6 foundry identification number for the U-7.7Nb plate \\
\hline $03 \mathrm{~K}-423$ & LANL/MST- 6 foundry identification number for the U-7.5 Nb plate \\
\hline $03 \mathrm{~K}-424$ & LANL/MST- 6 foundry identification number for the U-5.9Nb plate \\
\hline $03 \mathrm{~K}-425$ & LANL/MST- 6 foundry identification number for the U-5.6Nb plate \\
\hline 1YS & first yield stress/strength \\
\hline $2 \mathrm{YS}$ & second yield stress/strength \\
\hline $\mathrm{AC}$ & alternating current \\
\hline$A_{f}$ & austenite finish temperature \\
\hline $\mathrm{AQ}$ & as quenched \\
\hline$A_{s}$ & austenite start temperature \\
\hline $\mathrm{BF}$ & bright field \\
\hline CA & chemical analysis \\
\hline DIC & differential imaging contrast \\
\hline DU & depleted uranium \\
\hline e & elongation; engineering strain \\
\hline EPMA & electron probe microanalysis; also called (electron) microprobe \\
\hline GSAS & General Structure Analysis System (a LANL Rietveld software package) \\
\hline $\mathrm{HV}$ & microhardness \\
\hline ICPMS & inductively coupled plasma mass spectrometry \\
\hline LOM & (visible) light optical microscopy \\
\hline LAMIS & Los Alamos Materials System \\
\hline $\mathrm{M}_{\mathrm{f}}$ & martensite finish temperature \\
\hline$M_{s}$ & martensite start temperature \\
\hline PPMS & Physical Property Measurement System \\
\hline SEM & scanning electron microscope/microscopy \\
\hline TEM & transmission electron microscope/microscopy \\
\hline UTS & ultimate tensile stress/strength \\
\hline VAR & vacuum arc remelting \\
\hline wppm & weight parts per million \\
\hline WQ & water quench \\
\hline WR & war reserve \\
\hline $\mathrm{wt} \%$ & weight percent \\
\hline XRD & $\mathrm{x}$-ray diffraction \\
\hline
\end{tabular}




\title{
SYNTHESIS AND CHARACTERIZATION OF NONBANDED U-Nb PLATE MATERIAL
}

\author{
by \\ R. E. Hackenberg, R. M. Aikin, Jr., J. A. Balog, B. L. Bingham, R. Casey, A. Casteel, \\ I. Cordova, R. Forsyth, F. G. Garcia, D. Guidry, D. L. Hammon, W. L. Hults, \\ D. R. Korzekwa, A. M. Kelly, M. W. Koby, K. A. Lao, J. C. Lashley, M. F. Lopez, \\ R. McCabe, D. E. Nye, P. A. Papin, S. W. Quintana, J. L. Smith, D. F. Teter, D. J. Thoma, \\ T. Tucker, P. K. Tubesing, R. R. Trujillo, C. J. Vigil, and H. M. Volz
}

\begin{abstract}
This report describes the synthesis and characterization of four plates, two each of U-5.5Nb and U-7.5 $\mathrm{Nb}$ (nominal $\mathrm{wt} \%$ ) for aging studies described elsewhere. The plates were induction melted and cast into graphite molds that were unheated and $\sim 0.5$ inches thick to maximize the cooling rate and minimize large length-scale $\mathrm{Nb}$ segregation (banding). Microstructural images and electron microprobe traces observed after various processing stages, including casting, hot rolling, and homogenizing are documented. The as-cast microsegregation assumed the form of an isotropic cellular structure, with an amplitude of 3-15 wt $\% \mathrm{Nb}$ and 40-50 micron-length scales. Subsequent thermomechanical processing was shown to be sufficient to attain $\mathrm{Nb}$ compositional homogeneity on local scales of hundreds of microns. The results of chemical analysis and other characterization methods are given. The principal impurity elements (of the $40+$ elements measured) were carbon, boron, oxygen, tantalum, and iron. In all four plates, after homogenization, the $\mathrm{Nb}$ distribution across the entire plate cross-section showed minima at the plate faces and a broad maximum in the center, the differential being $0.5-0.7 \mathrm{wt} \%$ in $\mathrm{U}-7.5 \mathrm{Nb}$ and $0.2-0.5 \mathrm{wt} \%$ in $\mathrm{U}-5.5 \mathrm{Nb}$. None of the impurity elements showed statistically significant variations between the center $50 \%$ of the plate volume vs the outer $25 \%$. These plates were considered nonbanded and compositionally homogeneous for their proposed use because the required tensile, metallographic, and dilatometer specimens could be extracted from the fairly homogeneous center portion of the plate cross-section. Characterization of the phases and their transition temperatures by $\mathrm{x}$-ray diffraction and dilatometry in rapidly quenched specimens from the final product confirmed that the microstructure of this plate material was suitable for the intended aging studies. The as-quenched tensile response from multiple specimens taken from each plate showed some variability, especially in the ultimate tensile strength and elongation to failure. In general, $\mathrm{U}-5.5 \mathrm{Nb}$ has higher strength and less ductility than U-7.5 Nb, though both alloys exhibited the double yield behavior characteristic of banded $\mathrm{U}-6 \mathrm{Nb}$.
\end{abstract}




\section{INTRODUCTION}

Uranium- $6 \mathrm{wt} \% \mathrm{Nb}$ alloys have historically been produced with vacuum arc remelting (VAR) as the final melt step. This final VAR step results in a microstructure that is compositionally inhomogeneous, despite subsequent wrought processing. In particular, this VAR processed $\mathrm{U}-6 \mathrm{Nb}$ is compositionally banded on a scale of $0.1-1 \mathrm{~mm}$, with an amplitude of about $\pm 2 \mathrm{wt} \% \mathrm{Nb}$. This banding complicates attempts to understand both baseline properties and agingrelated changes in this material, especially because the $4-8 \mathrm{wt} \% \mathrm{Nb}$ range spans three metastable phases and a two-fold difference in as-quenched microhardness. Compositionally homogeneous $\mathrm{U}-\mathrm{Nb}$ alloys have been produced by arc melting and homogenization, but the ingot size is too small to yield mechanical test specimens (other than microhardness).

A goal of recent research efforts at LANL to understand U-Nb aging through the prism of mechanical properties required the production of larger-scale U-Nb alloys that were as compositionally homogeneous as possible. This report documents the synthesis and characterization results from such an effort to cast and thermomechanically process $\mathrm{U}-\mathrm{Nb}$ plates. Two alloy compositions were selected, U-5.5 wt $\% \mathrm{Nb}$ and U-7.5 $\mathrm{wt} \% \mathrm{Nb}$. Two plates were made of each composition; all four plates were processed the same except as noted.

\section{PLATE SYNTHESIS}

The cooling rate from the melt was identified as the key factor limiting the compositional homogeneity in the desired U-Nb alloys. A plate geometry was selected for the mold design to maximize the heat transfer rate out of the mold and to facilitate subsequent processing. The minimum final plate thickness needed to extract the desired tensile, compact tension and biaxial bulge test specimens was 0.275 inches $(0.25$-in. for the specimens +0.025 -in. allowance). In anticipation of plate shrinkage after solidification and a 50\% hot rolling reduction, a mold thickness of 0.560 inches was selected. The mold, crucibles, and stopper rods were made of $\mathrm{Y}_{2} \mathrm{O}_{3}$-coated 2020 graphite, and the mold design is shown in Figure 1. The molds were prefired before coating with $\mathrm{Y}_{2} \mathrm{O}_{3}$. Once coated with the $\mathrm{Y}_{2} \mathrm{O}_{3}$ (YZP type $\mathrm{Y}$ ) the mold was heated to above $750^{\circ} \mathrm{C}$ to burn off the binder. A new mold for $03 \mathrm{~K}-422$ was reused for $03 \mathrm{~K}-423$.

Likewise, a new mold for 03K-424 was reused for 03K-425.

The charges for melting consisted of Y12-produced U-6 $\mathrm{Nb}$ that was either diluted with Derby DU (U-5.5Nb plates) or enriched with a U-9 wt\% $\mathrm{Nb}$ master alloy (U-7.5 $\mathrm{Nb}$ plates). Their masses were weighed assuming perfect stoichiometry (i.e., with no biasing that would offset any preferential $\mathrm{U}$ or $\mathrm{Nb}$ losses.) The U-9Nb master alloy was prepared by nonconsumable electrode arc melting Y-12 U-6Nb with commercial high-purity Nb stock. The melting and gravity casting were done under vacuum in the K furnace of the MST- 6 foundry in June and July of 2003. The charge was induction melted, held $\sim 30$ minutes at $1,425^{\circ} \mathrm{C}$ to outgas and finally heated further to $1,500^{\circ} \mathrm{C}$ over $\sim 10$ minutes to add convective stirring immediately before pouring the charge. The mold was deliberately left unheated by an otherwise available second induction coil in order to obtain the maximum possible cooling rate. (Doing this carried the risk of producing a casting with significant voids.) Stray radiation from the crucible did in fact heat the mold slightly, to temperatures ranging over $60^{\circ} \mathrm{C}-250^{\circ} \mathrm{C}$, as measured by thermocouples inserted into small holes drilled in the mold. The thickness of the cast plates were all in the range 0.551-in. -0.556 -in., consistent with a small amount of shrinkage expected during cooling. 
After cooling, the hot top was cut away and discarded. Two large triangles were then cut off the top to make the plate a symmetric octagon to facilitate rolling. Portions of these triangles and chunks from the lower corners were carved out to carry out metallography and electron microprobe (EPMA) on the as-cast condition (see Figure 2). After this cutting step, the remaining octagonal plate mass was about $8.5 \mathrm{~kg}$.
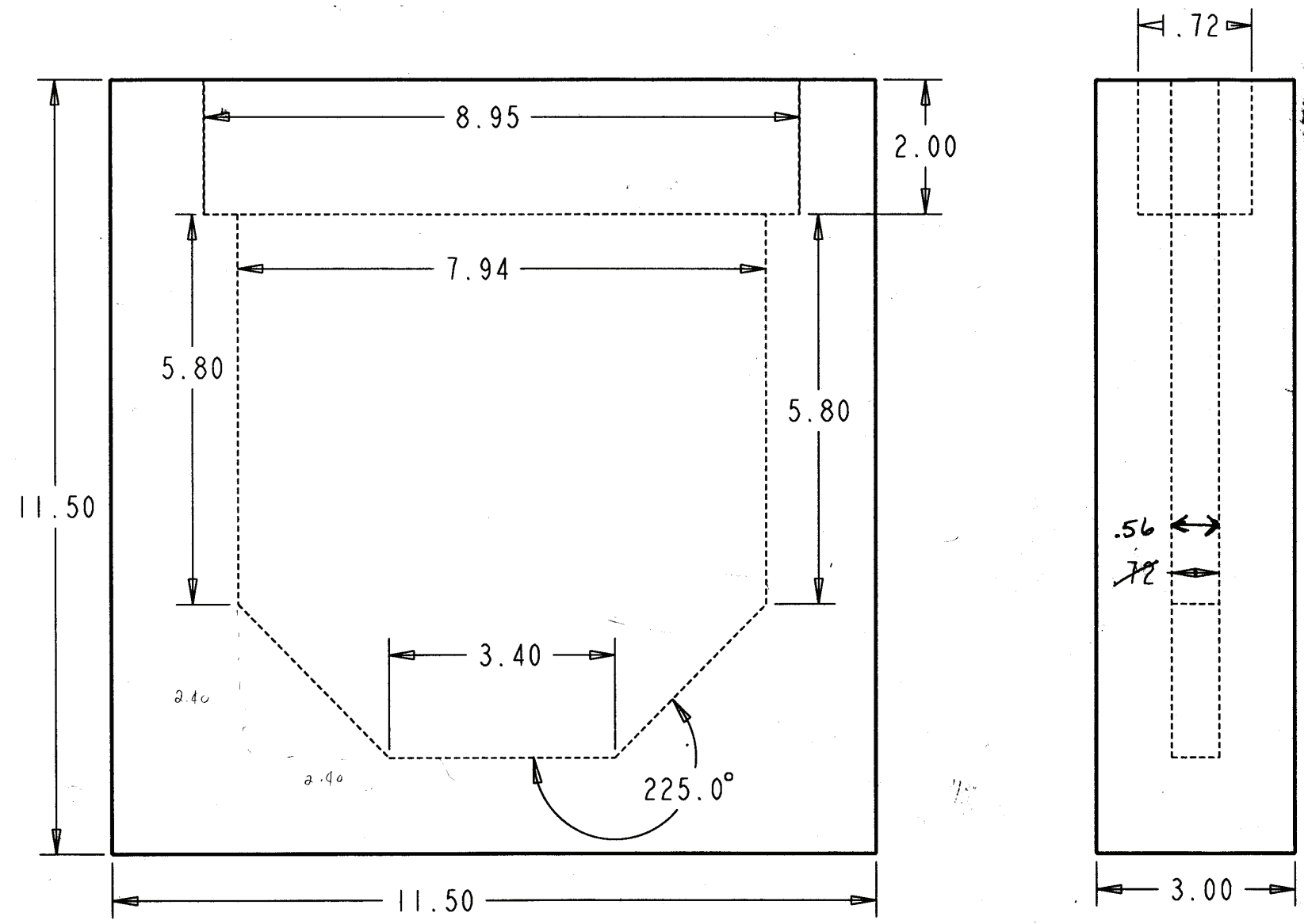

Figure 1. Graphite mold design used to cast 0.56-in.-thick semioctagonal U-Nb plates. Units are inches. The mold was made in two pieces to facilitate removal of the casting after cooling, though this is not indicated in this drawing. 


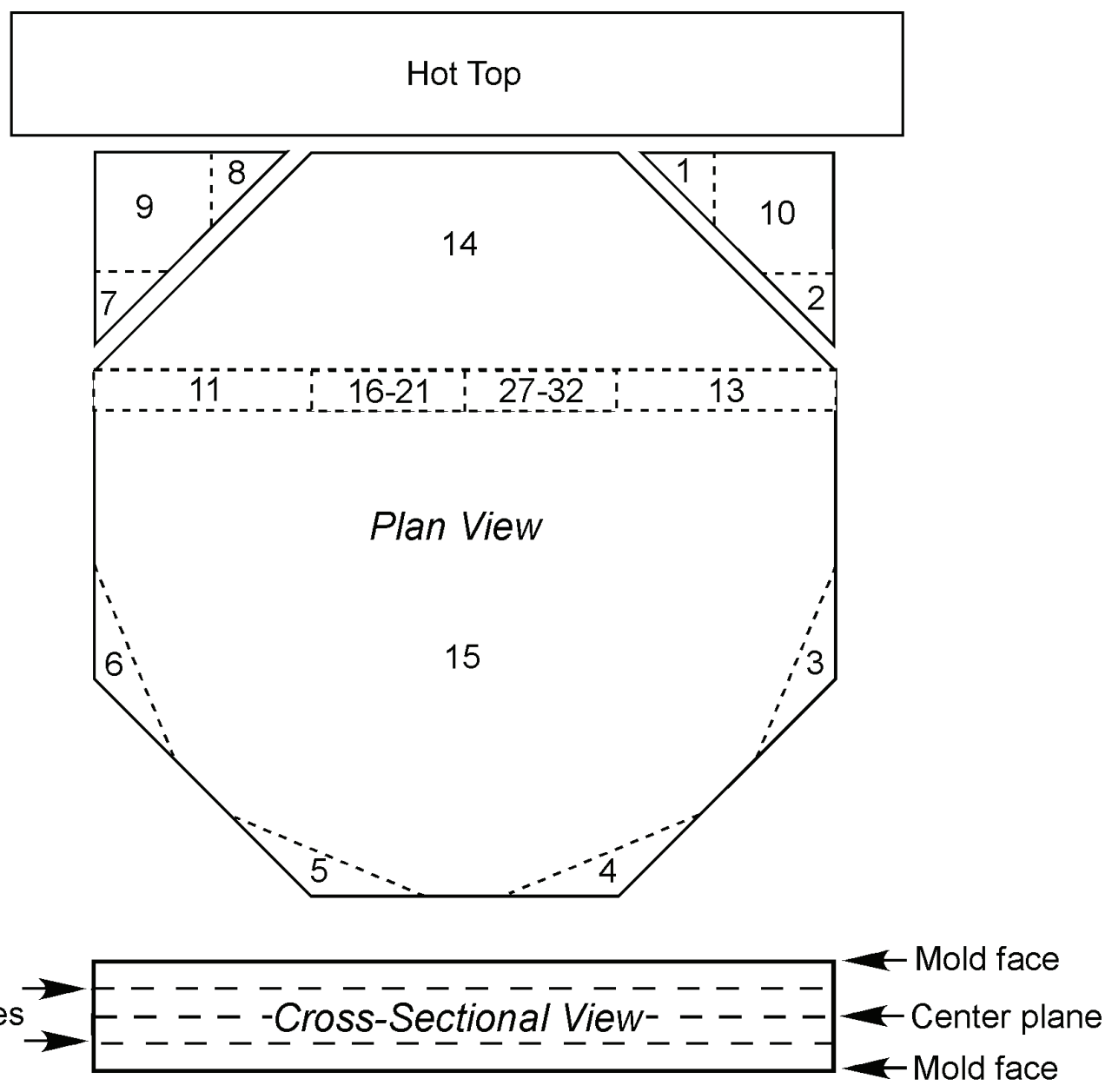

Figure 2. Sketch of plate carve-up. The numbers indicate locations from which specimens were extracted for characterization; dotted lines indicate how these numbered chunks were cut. Chunks 1-10 were cut before rolling, whereas the others were cut after rolling. Table 2 maps the location numbers with specific characterization steps. Among the solutionized-andwater-quenched specimens (both with and without artificial aging), dilatometer specimens were extracted from the lower portion of 14, while coupons and tensile specimens were taken from the upper portion of 15. 
To break down the as-cast structure and homogenize the nonuniform $\mathrm{Nb}$ distribution expected from coring (Rhines 1956), the plates were then thermomechanically processed as follows:

1. Prehomogenization anneal in a vacuum furnace to reduce the amounts of any brittle as-cast phases that might cause problems during subsequent rolling:
a. Heat at $10^{\circ} \mathrm{C} /$ minute to $1,000^{\circ} \mathrm{C}$ and hold 2 hours.
b. Cool to $850^{\circ} \mathrm{C}$ and hold 30 minutes.
c. Oil quench.

2. Hot rolling to $\sim 50 \%$ total reduction over 8 passes:
a. Preheat in a salt bath at $580^{\circ} \mathrm{C}$ for 30 minutes.
b. Heat to $850^{\circ} \mathrm{C}$ in an air furnace.
c. Hot roll pass.
d. Either reheat to $850^{\circ} \mathrm{C}$ for $8-10$ minutes in the air furnace (after passes $1-7$ ) or water quench (after pass 8).

3. Cut a strip of coupons from the center of the plate for as-rolled metallography, test homogenizations and subsequent EPMA.

4. Homogenization anneal in a vacuum furnace to remove any remaining microsegregation:

a. Heat at $10^{\circ} \mathrm{C} /$ minute to $1,000^{\circ} \mathrm{C}$, and hold 6 hours.

b. Furnace cools to ambient temperature.

5. Cut off and discard a 0.75-in.-wide strip from the entire plate perimeter as a precaution against nonuniform microstructure at the plate edges.

6. Machine specimens for baseline plate characterization and aging studies.

Steps 1 and 2 were done on July 16 and July 23-24, 2003, respectively. Step 4 was done on November 18, 2003. Steps 1 and 4 were done in the Wellman furnace in the MST-6 fabrication area; and the vacuum level during heating peaked at 20 micron $\mathrm{Hg}$, presumably due to outgassing and ultimately settled down at 2-3 micron $\mathrm{Hg}$. The directions of the rolling passes were along the four principal axes of the octagonal plate and done in the sequence 0-90-45-135-0-90-45-135 degrees in order to preserve the octagonal symmetry. During rolling, moderate oxidation was qualitatively observed for all plates except for $03 \mathrm{~K}-424$, which experienced heavy oxidation. The origin of this instance of heavier oxidation is unclear.

Table 1 lists foundry identification numbers, compositions and dimensions for each plate. At the time this report was issued, specimens have been machined only out of the $03 \mathrm{~K}-422$ and $03 \mathrm{~K}-425$ plates. The other two plates, $03 \mathrm{~K}-423$ and $03 \mathrm{~K}-424$, are being held in reserve for future studies, including any that require biaxial bulge or compact tension specimens. 


\begin{tabular}{|l|l|l|l|l|}
\hline \multicolumn{4}{|l|}{$\begin{array}{l}\text { Table 1. Plate characteristics. The error given for the Nb composition is the standard } \\
\text { deviation of multiple measurements. The center 50\% analysis is for material sampled } \\
\text { from the contiguous volume between the quarter planes in Figure 2. The outer 25\% } \\
\text { analysis is for material sampled from the two noncontiguous volumes between the quarter } \\
\text { planes and their nearest mold faces (with any surface scale ground off beforehand). }\end{array}$} \\
\hline MST-6 Foundry Identification Number & $\mathbf{0 3 K - 4 2 2}$ & $\mathbf{0 3 K - 4 2 3}$ & $\mathbf{0 3 K - 4 2 4}$ & $\mathbf{0 3 K - 4 2 5}$ \\
\hline Nominal wt\% Nb & 7.50 & 7.50 & 5.50 & 5.50 \\
\hline Analyzed wt\% Nb, center 50\% (ICPMS) & $7.69 \pm 0.33$ & $7.46 \pm 0.12$ & $5.95 \pm 0.08$ & $5.60 \pm 0.56$ \\
\hline Analyzed wt\% Nb, center 50\% (EPMA) & $7.75 \pm 0.13$ & $7.16 \pm 0.14$ & $5.65 \pm 0.12$ & $5.30 \pm 0.21$ \\
\hline Analyzed wt\% Nb, outer 25\% (ICPMS) & $6.93 \pm 0.10$ & $6.79 \pm 0.69$ & $5.43 \pm 0.05$ & $5.39 \pm 0.11$ \\
\hline Analyzed wt\% Nb, outer 25\% (EPMA) & $7.29 \pm 0.21$ & $6.60 \pm 0.24$ & $5.13 \pm 0.37$ & $5.07 \pm 0.11$ \\
\hline Nominal mold thickness (in.) & 0.560 & 0.560 & 0.560 & 0.560 \\
\hline As-cast plate thickness (in.) & 0.556 & 0.552 & 0.551 & 0.552 \\
\hline Desired as-rolled thickness (in.) & 0.275 & 0.275 & 0.275 & 0.275 \\
\hline Actual as-rolled thickness (in.) & 0.201 & 0.278 & 0.265 & 0.255 \\
\hline Actual as-rolled thickness (micron) & 5105 & 7061 & 6731 & 6477 \\
\hline Width after rolling (in.) & 13.2 & 10.4 & 10.5 & 11.5 \\
\hline \hline
\end{tabular}

\section{CHARACTERIZATION METHODS}

\subsection{Metallography and Microprobe}

This section documents characterization of the plates at various stages of processing, mainly by light optical microscopy (LOM) and microprobe (the common term for electron probe microanalysis, EPMA). Table 2 lists the relevant job numbers in the MST-6 Characterization database and the techniques employed for a given job. Table 3 lists the unique material pedigree identifiers in the Los Alamos Materials Information System (LAMIS) Metals and Ceramics database where much of the data obtained during this plate production study and subsequent $\mathrm{U}-\mathrm{Nb}$ aging studies are being archived. 


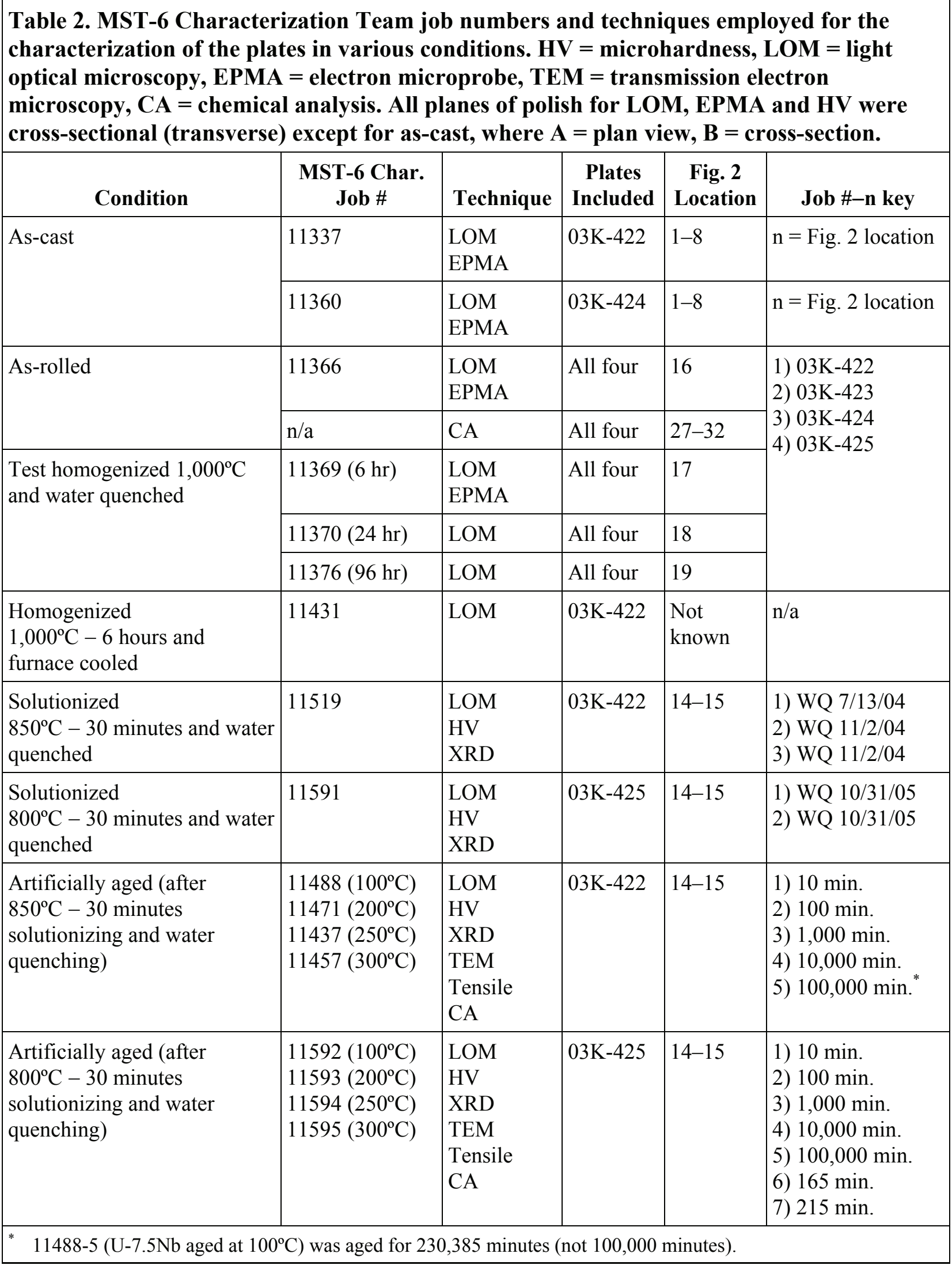



Table 3. Material Pedigree identification numbers for characterization of the plates in various conditions as listed in the Los Alamos Materials Information System (LAMIS) Metals and Ceramics Granta database. The number $<n>$ is given for ID of the form MP2006- $<$ n $>$.

\begin{tabular}{|l|c|c|c|c|}
\hline \multicolumn{1}{|c|}{ Condition } & $\mathbf{0 3 K - 4 2 2}$ & $\mathbf{0 3 K - 4 2 3}$ & $\mathbf{0 3 K - 4 2 4}$ & $\mathbf{0 3 K - 4 2 5}$ \\
\hline As-cast & 2 & 3 & 4 & 5 \\
\hline As-rolled & 6 & 7 & 8 & 9 \\
\hline Test homogenized and water quenched & 10 & 11 & 12 & 13 \\
\hline Homogenized and furnace cooled & 14 & 15 & 16 & 17 \\
\hline Solutionized and quenched & 18 & 19 & 20 & 21 \\
\hline $\begin{array}{l}\text { Artificially aged (after solutionizing and water } \\
\text { quenching) }\end{array}$ & 22 & 23 & 24 & 25 \\
\hline \hline
\end{tabular}

Metallographic preparation for LOM was done as follows. Specimens were epoxy mounted and cured without the addition of any external heating. They were mechanically ground with $\mathrm{SiC}$ up to 800 grit, polished with 3 micron diamond and finally 1 micron diamond. They were then electropolished 2-3 seconds at 3-4 volts with 5\% phosphoric acid and then electroetched 3-5 seconds at 4-5 volts with 10\% oxalic acid. Imaging was done under brightfield illumination unless otherwise specified as differential imaging contrast (DIC) illumination in the Figure caption.

EPMA measurements were made on a JEOL 840 fitted with wavelength spectrometers. Pure elemental standards were used to calibrate for peak positions and to determine K-ratios for the unknowns. These standards were then tested on known alloy compositions of U-Nb (homogeneous samples with wet chemistry performed on them). Measurements were made at $15 \mathrm{kV}$ and approximately $20 \mathrm{nA}$. The Bastin ZAF correction scheme was used after comparisons with other schemes. The as-measured elemental total $\% \mathrm{Nb}+\% \mathrm{U}$ was almost always in the $99 \%-101 \%$ range. The $\mathrm{Nb}$ amounts reported here were normalized assuming $\% \mathrm{Nb}+\% \mathrm{U}=100 \%$.

\subsection{Chemical Analysis}

Chemical analysis was carried out on two types of specimens: (1) as-rolled coupons 27-32 (Figure 2) from all four plates that were precut into sections constituting either the center $50 \%$ or outer $25 \%$ of the plate cross-section and (2) slices taken from the nominal 0.1-in. diameter gage sections ( $\sim 50 \%$ of the plate cross-section) of tensile specimens that came from the fully homogenized $03 \mathrm{~K}-422$ and $03 \mathrm{~K}-425$ plates and were subsequently solutionized, water quenched, and aged in vacuum encapsulations at temperatures of $100^{\circ} \mathrm{C}, 200^{\circ} \mathrm{C}, 250^{\circ} \mathrm{C}$, and $300^{\circ} \mathrm{C}$ for times ranging from 10 to 100,000 minutes before being tested to failure. Care was taken to grind off any scale from the coupon surfaces before analysis. Between one third to one 
half of the specimens analyzed for any given element came from the as-rolled coupons, the balance from the tensiles. Analyses of 2-27 specimens contributed to the average and standard deviation quoted for each element. The most typical number of specimens was in the 3-8 range.

Chemical analysis was done using MST-6 capabilities. Samples were prepared for hydrogen, oxygen, nitrogen, carbon, and sulfur analysis by sequential rinsing. The samples were first rinsed in a 10\% nitric acid bath for 30 seconds, followed by a quick deionized water rinse. Next, the samples were rinsed in an acetone bath for 30 seconds, with a final 30 second rinse in ethanol. The samples were dried using a heat gun.

Hydrogen, oxygen, and nitrogen were analyzed by inert gas fusion. The hydrogen was analyzed (Lao and Teter 2004) using a LECO EF-400EN analyzer, while the oxygen and nitrogen were analyzed using a Horiba EMGA-650 analyzer. The LECO EF-400EN uses argon as a carrier gas with a thermal conductivity detector to measure the hydrogen $\left(\right.$ as $\left.\mathrm{H}_{2}\right)$ while the Horiba EMGA-650 uses helium as a carrier gas with an infrared absorption detector to measure oxygen (as $\mathrm{CO}$ ) and a thermal conductivity detector to measure nitrogen (as $\mathrm{N}_{2}$ ). Graphite crucibles were used in both instruments. Tin flux, $0.2 \mathrm{~g}$ for the oxygen/nitrogen analysis and $1 \mathrm{~g}$ for the hydrogen analysis, was added to aid sample melting. NIST-traceable, LECO-certified standards were used for calibration. A different LECO-certified standard was used as a check standard after the calibration and after every 10, or fewer, sample runs. Blank checks that included both the crucible and flux were run at the same interval as the check standards. Sample sizes ranged from approximately $0.3 \mathrm{~g}$ for the oxygen/nitrogen analysis to $1-2 \mathrm{~g}$ for the hydrogen analysis.

Carbon and sulfur were analyzed by combustion using a Horiba EMIA-8200 analyzer. The sample was heated using a high-frequency induction furnace in an oxygen stream to convert the carbon in the sample to $\mathrm{CO}$ and $\mathrm{CO}_{2}$ and the sulfur to $\mathrm{SO}_{2}$, for detection by infrared absorption. Samples were placed in ceramic crucibles with an accelerator, $1.5 \mathrm{~g}$ tungsten and $0.3 \mathrm{~g}$ tin, to aid combustion. NIST-traceable LECO- or Alpha-certified standards were used for calibration. A different LECO- or Alpha-certified standard was used as a check standard after the calibration and after every 10, or fewer, sample runs. Blank checks that included both the crucible and accelerator were run at the same interval as the check standards. Samples were approximately $1 \mathrm{~g}$ each.

All other reported elements were measured by inductively coupled plasma mass spectrometry (ICPMS). Before ICPMS analysis, each sample was carefully dissolved in a combination of reagents including $4 \underline{\mathrm{M}} \mathrm{HNO}_{3} \cdot 0.01 \% \mathrm{HF}$, concentrated $\mathrm{HCl}$, deionized water, and concentrated HF. Once dissolution was complete, these mixtures were diluted with $4 \mathrm{M} \mathrm{HNO}_{3} \cdot 0.01 \% \mathrm{HF}$ to an appropriate final volume. Niobium concentrations were determined from this solution following additional dilution in $2 \% \mathrm{HNO}_{3}$. Trace element measurements required an additional chemical separation step. In order to minimize adverse matrix effects, a portion of each sample solution was passed through an extraction chromatography column containing Eichrome Uteva resin ( $2 \mathrm{ml}$ bed of 50-100 $\mu \mathrm{m}$ bead size). This resin effectively separates the uranium matrix from trace analytes of interest; uranium is retained on column while analytes are selectively eluted by choosing an eluant of appropriate acid concentration. Column eluant was collected and further diluted before analysis by ICPMS.

A Perkin Elmer Elan 6100 ICPMS was used for quantitative analysis using internal standardization and external calibration methods. Before sample analysis, instrument response was calibrated using a calibration blank and three calibration standard mixes containing different concentrations of the analytes of interest. A linear calibration curve (counts/second vs. 
concentration) was established for each analyte using the calibration data. Plate samples and quality control samples were then analyzed, and concentration data were derived from the calibration curve. Quantitative analyses of several elements, including boron, calcium, sodium, iron, silicon, and phosphorous, are problematic when using ICPMS because of either low abundance sensitivity or molecular interferences — not an unexpected limitation of the technique. Silicon and calcium, being the most problematic of these elements, were not included in the analysis results published in this report.

\subsection{Other Characterization}

Following homogenization, specimens were solutionized, water quenched, and subjected to $\mathrm{x}$-ray diffraction (XRD) and dilatometry to examine the phases present and their transformations. XRD was carried out at ambient temperature using a laboratory diffractometer at $40 \mathrm{kV}$. Surface damage and other artifacts were removed by subjecting the specimens to 3 minutes of Jackson's polish $\left(35 \% \mathrm{H}_{2} \mathrm{O}, 60 \% \mathrm{H}_{3} \mathrm{PO}_{4}, 5 \% \mathrm{H}_{2} \mathrm{SO}_{4}, 12 \mathrm{~V}\right.$, room temperature) (Jackson, Johns, and Calabra 1967). Figure 3 shows the effect of various polishing times. Long count times were used, $2 \theta$ varied from $20^{\circ}$ to $148^{\circ}$ and $\mathrm{CeO}_{2}$ powder standard was used for internal calibration. Full-pattern Rietveld analysis was done on the polycrystalline diffraction patterns using GSAS (Larson and Von Dreele 1986).

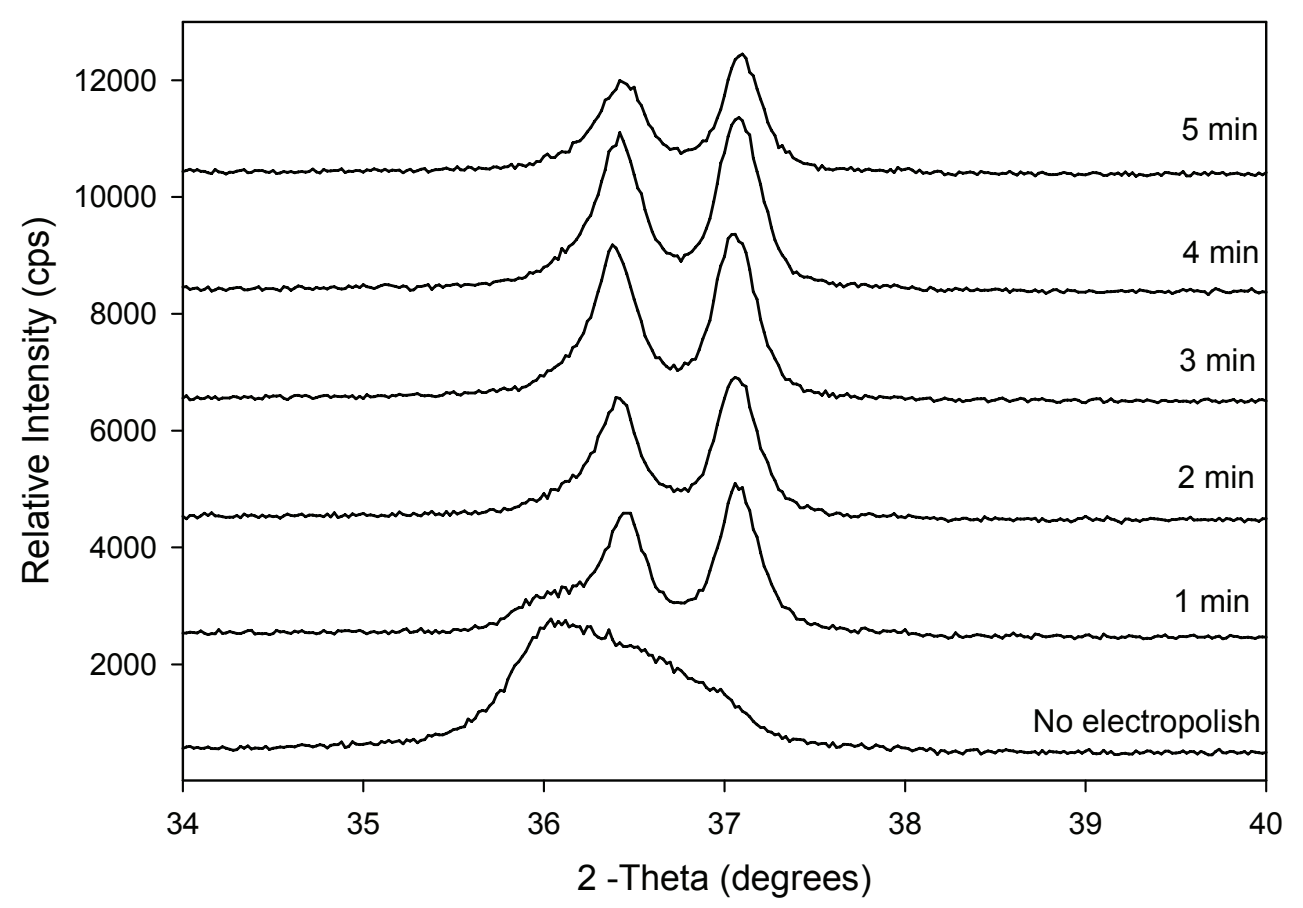

Figure 3. Change in appearance of $X$-ray diffraction data with electrochemical etch time for as-quenched $03 \mathrm{~K}-422$ (U-7.7Nb actual). The principal $\gamma^{\circ}$ peaks sharpen, and the damage effects from mechanical surface preparation weaken as time increases. Three minutes were found to be optimal for this sample and were subsequently used for both $03 K-422$ and $03 K-425$ in all conditions (as-quenched and aged). Intensities have been staggered for easier viewing. 
Phase transformation signals were determined by dilatometry on specimens of $3 \mathrm{~mm}$ diameter and $10 \mathrm{~mm}$ length. All specimens were rapidly heated from ambient to $925^{\circ} \mathrm{C}$ in 60 seconds and held there for 3 seconds. Rapid quenching with He gas (30 psi line pressure) allowed the specimen to reach $50^{\circ} \mathrm{C}$ in about 10 seconds, giving cooling rates sufficient to mark out the martensite transition temperatures without interference from other reactions. Conversely, slow cooling allowed any diffusional transformation signals to be observed. Multiple cycles were run on each specimen examined, with highly reproducible heating and cooling curves generated from runs on the same temperature-time profile, even when distinct transition signatures were absent. Electrical resistance measurements were done on a Quantum Design Physical Property Measurement System (PPMS) between $298 \mathrm{~K}$ and 4.6 K. Measurements were made by four terminal (spot-welded $\mathrm{Pt}$ wire that was annealed) AC transport resistance. Excitation settings were $10 \mathrm{~mA}, 13 \mathrm{~Hz}, 1 \mathrm{~s}$ average.

Tensile testing was done on solutionized-and-water-quenched specimens with a screwdriven machine at a strain rate of $0.001 / \mathrm{s}$. Strain was measured with an extensometer. Any visible oxide scale on the tensile specimens after heat treating was removed by intermittent electropolishing at 12 volts in a solution of $85 \%$ phosphoric acid $-2 \%$ sulfuric acid $-13 \%$ water. The specimen geometry is shown in Figure 4. Fractographs were taken in a SEM operating at $10 \mathrm{kV}$. Strengths, moduli, and elongations were measured from the stress-strain data, while the $\%$ reduction in area was derived from diametral measurements of the fracture regions on the actual specimens.

\section{CHARACTERIZATION AFTER CASTING AND ROLLING}

As-cast metallography was done on the 8 corners of castings $03 \mathrm{~K}-422$ and $03 \mathrm{~K}-424$ from coupons taken from positions $1-8$, all within $\sim 0.75$ inches of the plate edge, at locations shown on Figure 2. No as-cast metallography was done on regions further from the edge than this.

Figure 5 shows optical micrographs of the as-cast microstructure of the $03 \mathrm{~K}-422$ $\mathrm{U}-7.5 \mathrm{Nb}$ plate, with the variable etching contrast indicative of coring (microsegregation) (Rhines 1956). This coring had wavelengths in the 40-50 micron range. The coring wavelength did not show any systematic trend as a function of:

1. position on the plate $(1-8)$,

2. plane of polish orientation (cross-section vs plan view), or

3. distance from the mold face (center plane vs quarter plane vs mold face).

The uniformity of coring wavelength indicates that the entire plate (at least near the edges) solidified at more or less the same rate. Spongy coring patterns were observed throughout, which appeared to be isotropic because there was no discernible difference between plan and crosssectional views. The equiaxed white (nonetching) areas were probably the primary cells (or dendrites whose arms had all coarsened or broken off) that were the first to solidify. The resistance to etching indicates that these first-formed regions had $\mathrm{Nb}$ enrichment, a fact consistent with the slope of the solidus and liquidus lines on the U-Nb phase diagram (Koike et al., 1998) (which favors Nb-rich solids being the first to form from the melt). The only discernible microstructural variation was the qualitative observation that going from the top to the bottom of the casting the carbide inclusions were increasingly layered $\left(\mathrm{Nb}_{2} \mathrm{C}\right.$ in the center, surrounded by UC). 


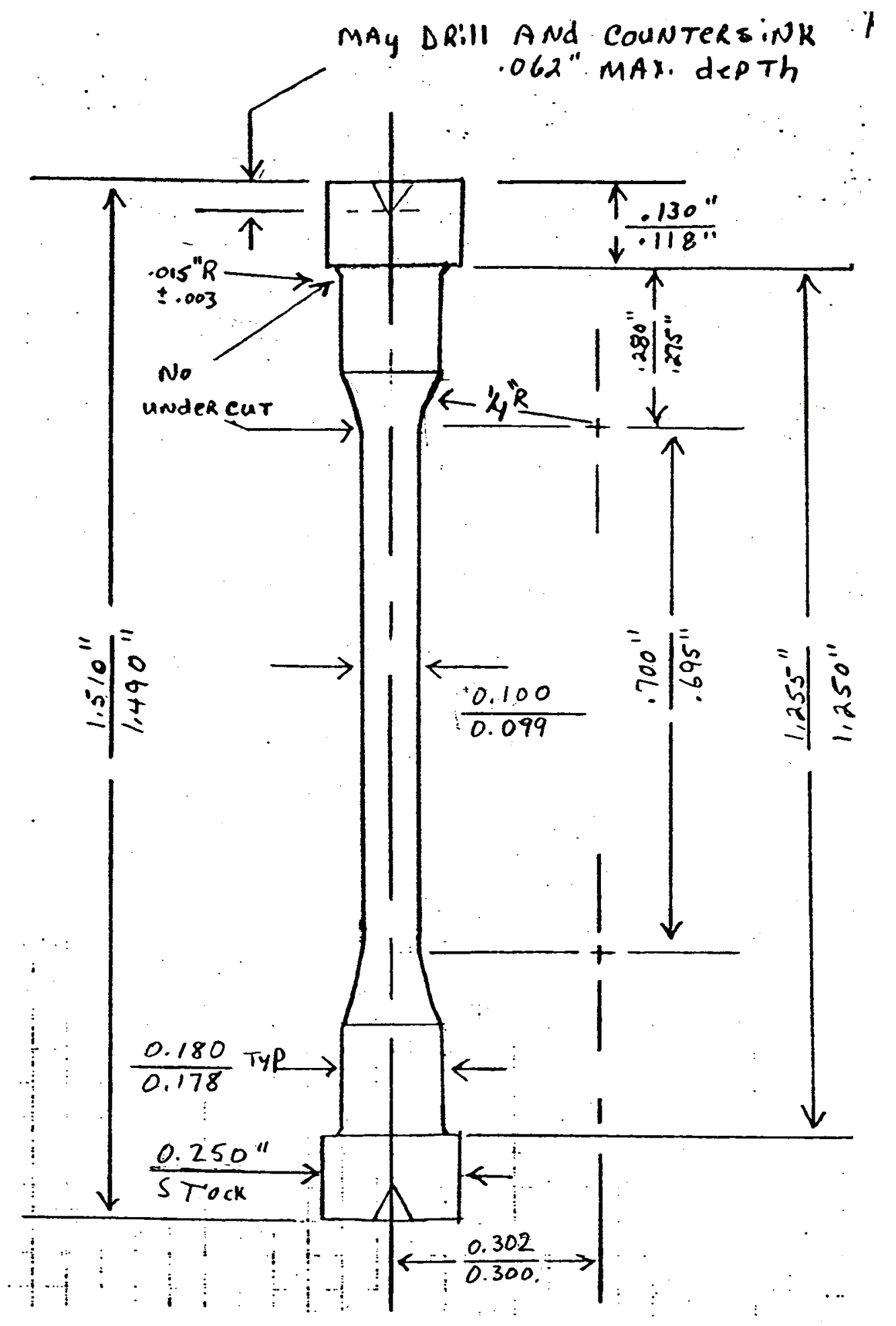

Figure 4. Cylindrically-symmetric tensile specimen geometry used in this study. Units are in inches. 


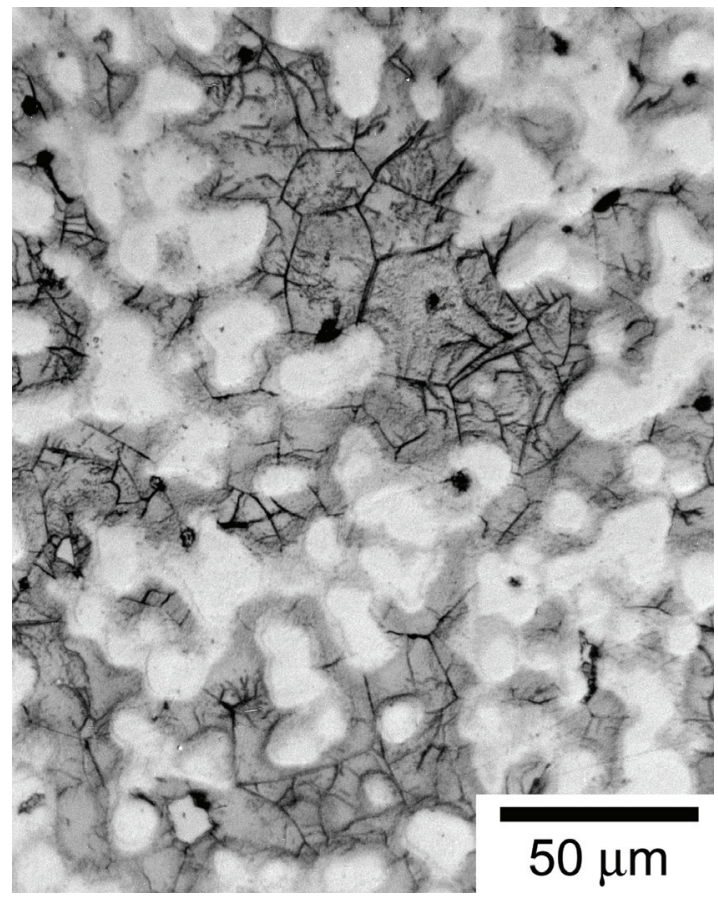

(a)

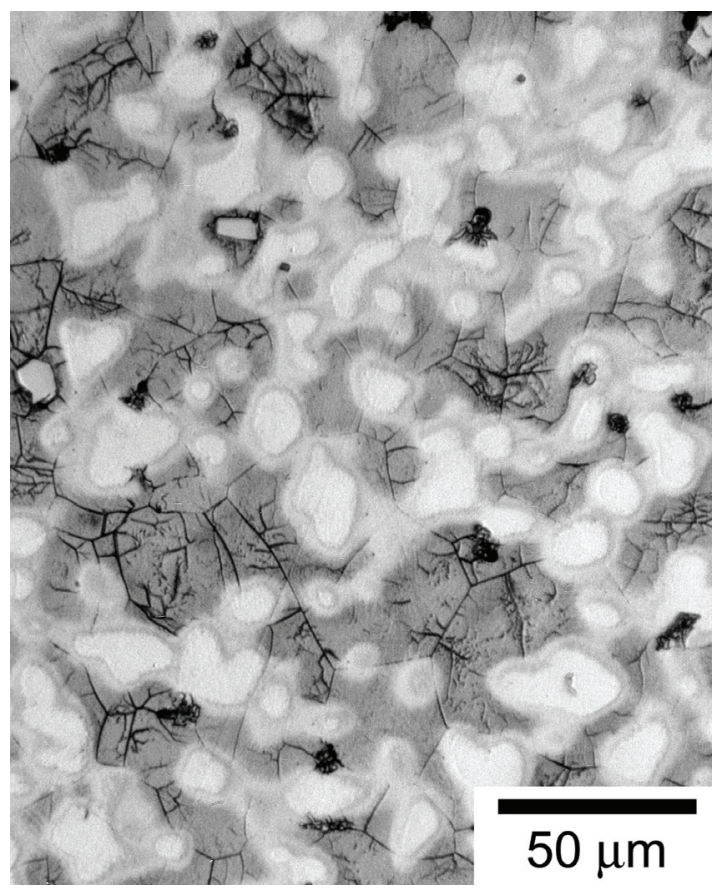

(b)

Figure 5. As-cast microstructure, taken from the location 1, center plane of 03K-422. (a) plan view and (b) cross-sectional view. The white areas that resist etching are likely Nb-enriched.

Figure 6 shows the as-cast structure of the $03 \mathrm{~K}-424 \mathrm{U}-5.5 \mathrm{Nb}$ plate, which also shows coring patterns with wavelengths comparable to $03 \mathrm{~K}-422$. The prior gamma grain boundaries etch more distinctly, with a solid-state cellular decomposition product seen growing out from these grain boundaries, as would be expected for moderate-to-slow cooling rates at temperatures below the $650^{\circ} \mathrm{C}$ monotectoid isotherm on the U-Nb phase diagram (Eckelmeyer 1984, Koike et al., 1998). Although the sponginess is less distinct than in the higher-Nb 03K-422, the microstructure still showed signs of primary cellular growth (from the melt) of Nb-rich regions. No position (1-8 or center-to-mold face) or plane of polish variations in microstructure or coring patterns were observed, making $03 \mathrm{~K}-424$ isotropic, similar to the findings for $03 \mathrm{~K}-422$.

The coring patterns in 03K-422 measured by EPMA are shown in Figure 7. Like the optical micrographs, there is little difference in the overall coring pattern between different planes of polish orientations $(\mathrm{a}-\mathrm{b}$ and $\mathrm{e}-\mathrm{f})$ or position relative to the mold face $(\mathrm{b}-\mathrm{c}-\mathrm{d})$. The fine scale scans (e-f) show that the amplitude of $\mathrm{Nb}$ segregation is $3-14 \mathrm{wt} \% \mathrm{Nb}$. In general, the $\mathrm{Nb}$-rich peaks occupy a smaller fraction of the microstructure than the $\mathrm{Nb}$-lean valleys, consistent with the asymmetry of the amplitude range with respect to the bulk nominal composition of $7.5 \mathrm{wt} \%$. 


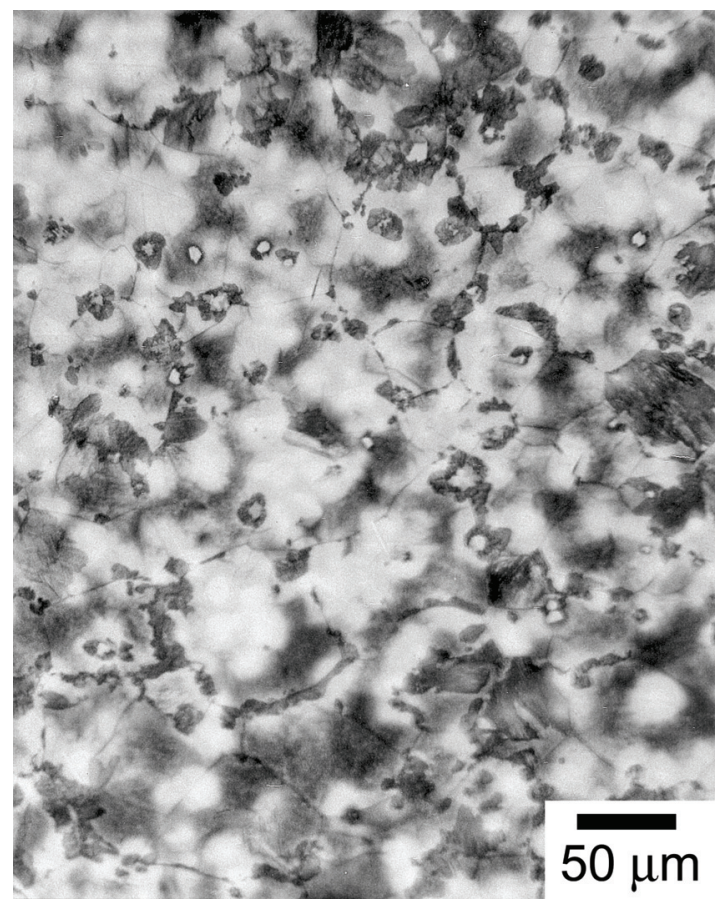

(a)

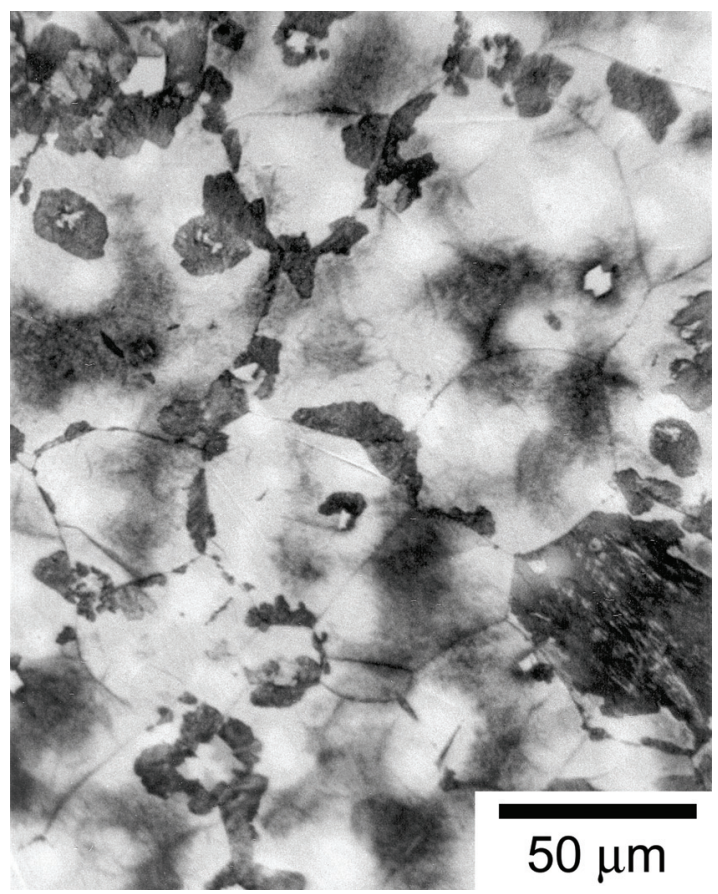

(b)

Figure 6. As-cast microstructure, taken from the location 1, center plane of 03K-424. Both (a) and (b) are cross-sectional views. Dark-etching cellular decomposition product is observed.

Figure 8 shows the microstructure in the as-rolled condition, with mild deformation evident. These as-rolled microstructures showed no spatial variation across the plate crosssection (mold face to center plane). The $1,000^{\circ} \mathrm{C}, 2$-hour prehomogenization, and the $850^{\circ} \mathrm{C}$ heating before each rolling pass clearly has reduced the coring amplitude by a significant amount, seen in Figure 9.

\section{CHARACTERIZATION AFTER HOMOGENIZATION}

Figures 10 and 11 show the microstructures following the test homogenization of $1,000^{\circ} \mathrm{C}$ for 6 hours (ended with a water quench) on coupons taken from the as-rolled plates. The equiaxed prior gamma grains, martensite twins, and carbide inclusions are readily observable in this annealed condition. These as-homogenized microstructures showed no spatial variation across the plate cross-section (mold face to center plane). The microprobe results in Figure 12 for this condition show that the $\mathrm{Nb}$ distribution has been leveled out (to within $\pm 0.1 \mathrm{wt} \%$ of the local mean) on local length scales of hundreds of microns. This homogenization time was therefore used for all four plates. The homogenizations of test coupons and the remainder of the plates differed in that the plates were vacuum annealed and furnace cooled to minimize distortion, whereas the test coupons were annealed under quartz encapsulation and water quenched. 


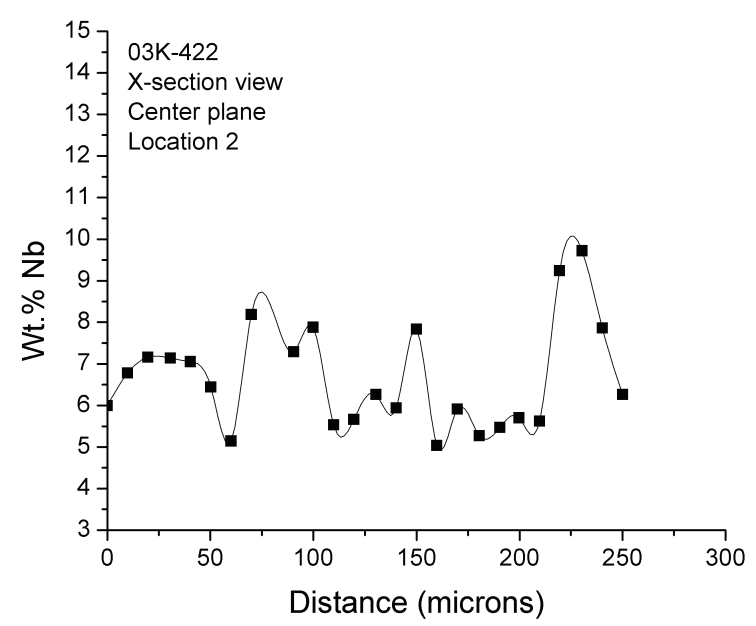

(a)

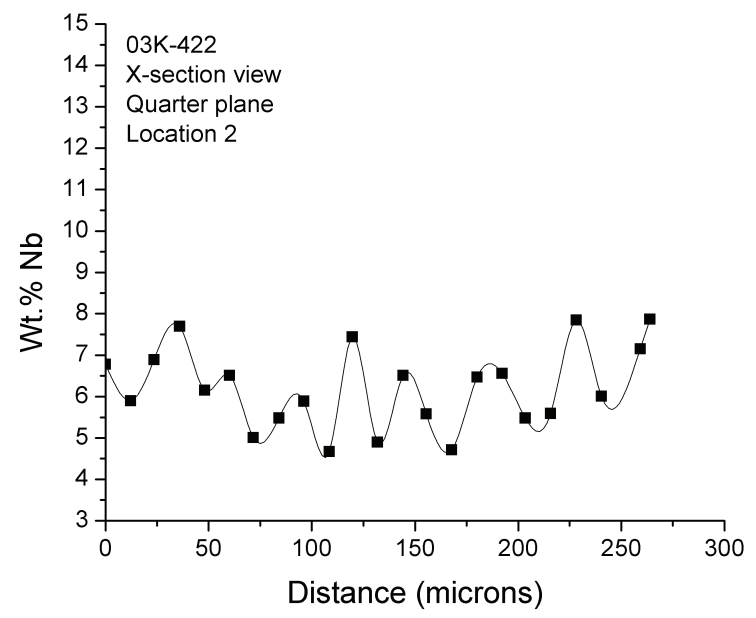

(c)

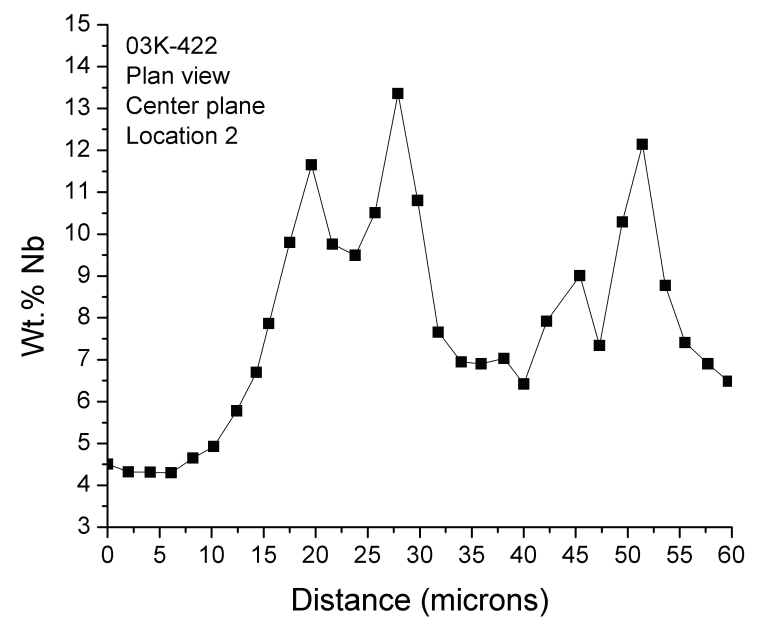

(e)

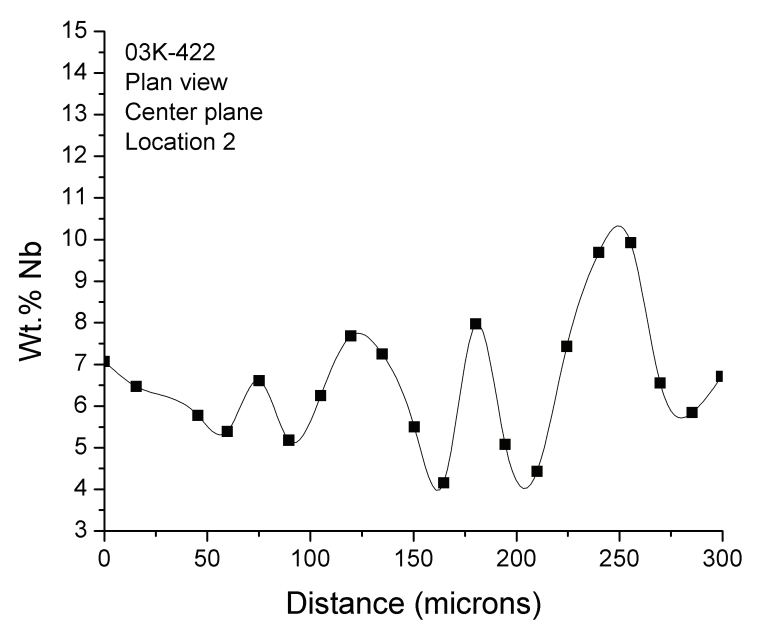

(b)

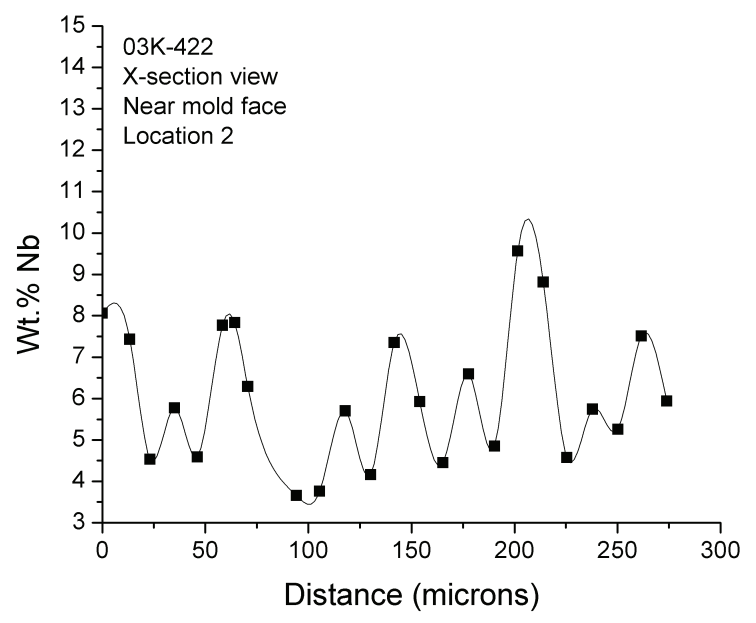

(d)

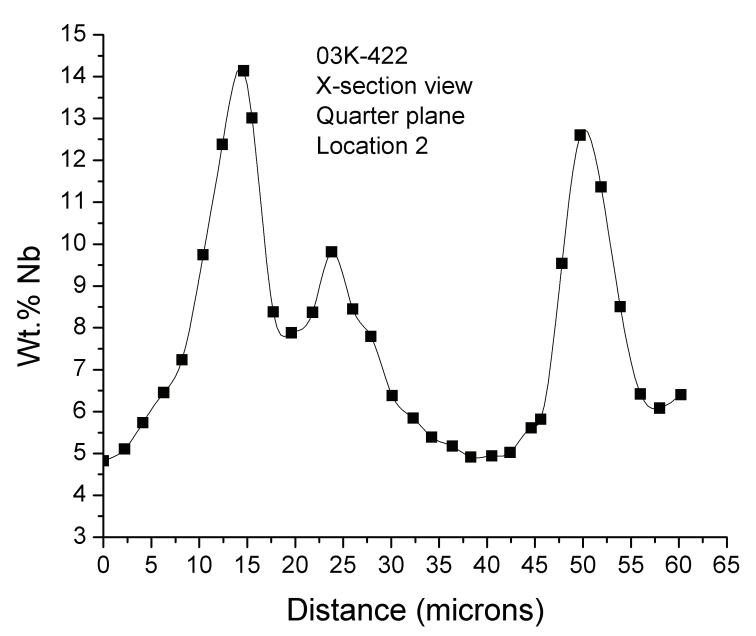

(f)

Figure 7. As-cast microprobe traces from 03K-422 at coarse (a-d) and fine (e-f) scales. 


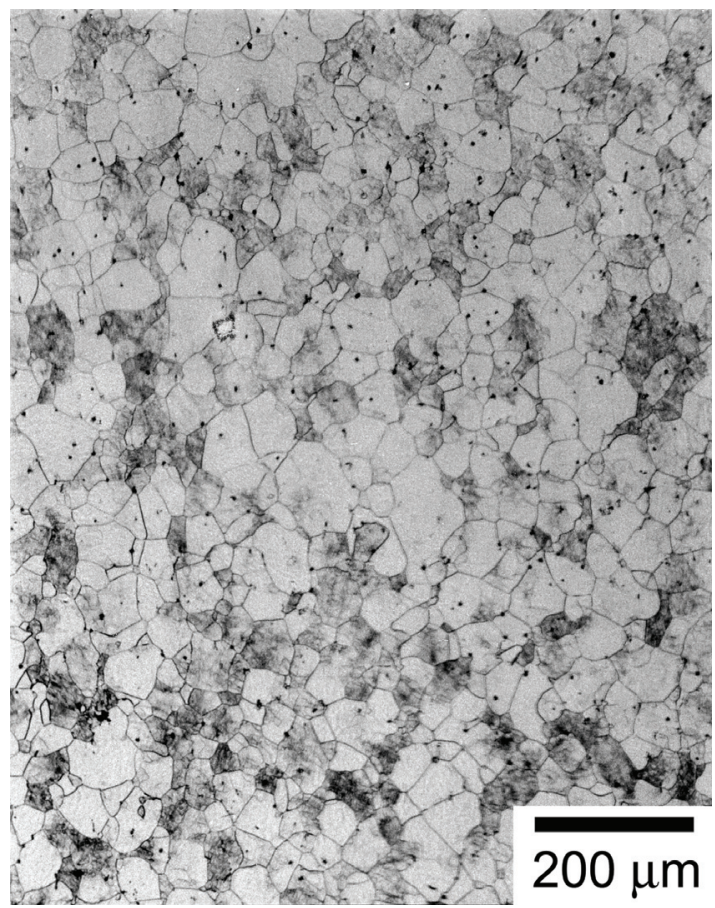

(a)

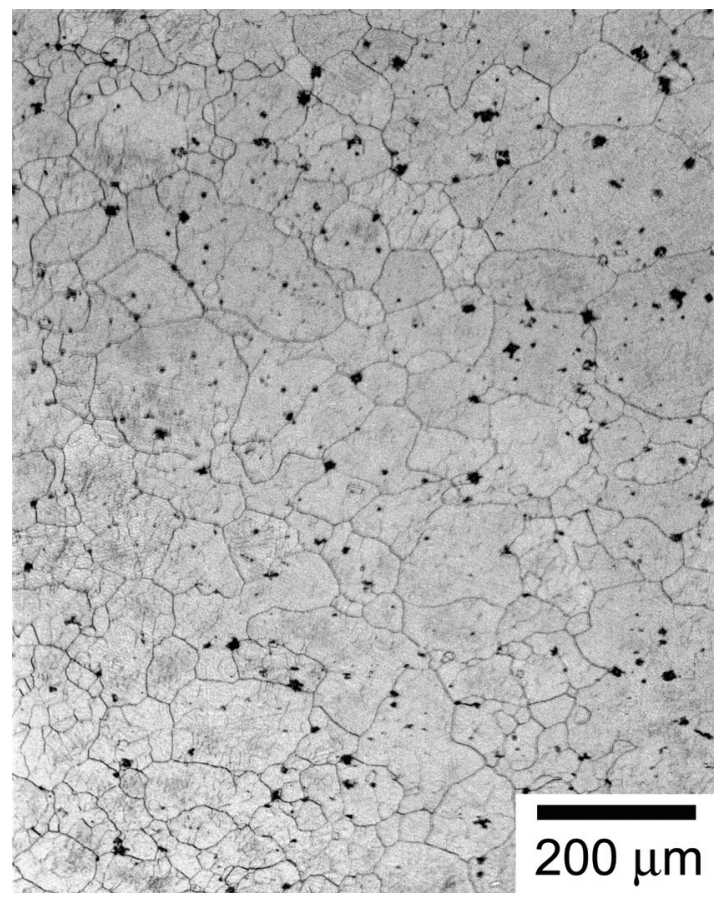

(c)

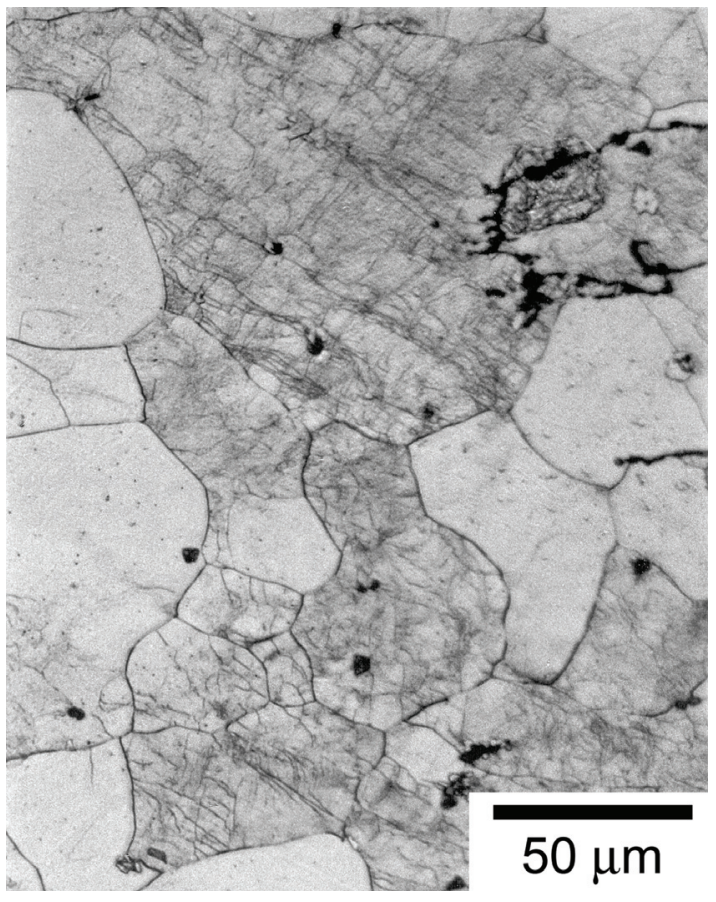

(b)

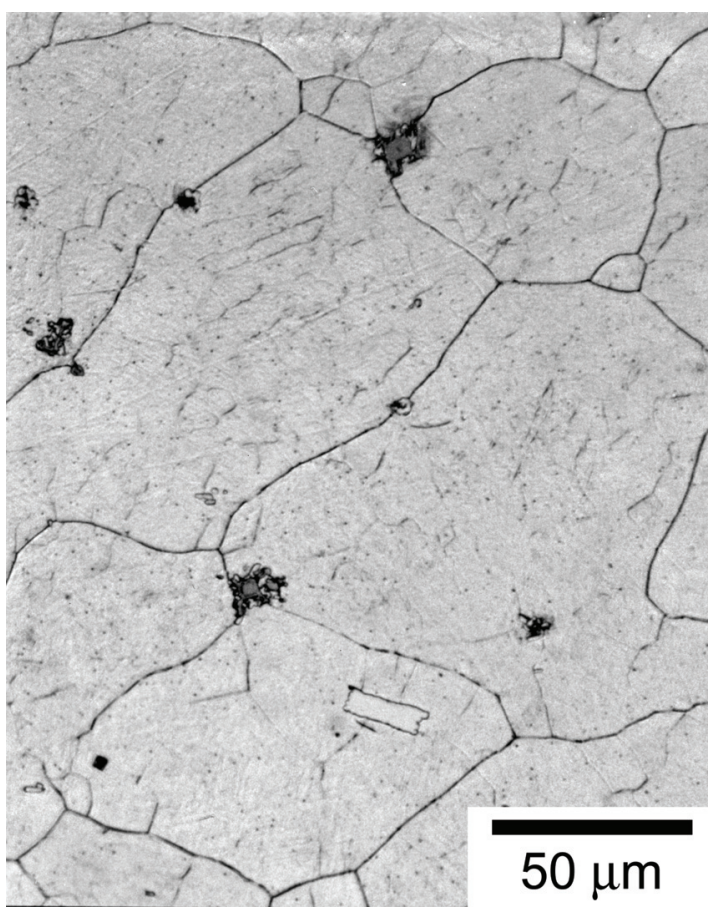

(d)

Figure 8. Post-rolling optical micrographs of 03K-422 (a, b) and 03K-424 (c, d), cross-section plane of polish. The contrast resulting from coring is significantly reduced compared to the as-cast state. Dislocation networks resulting from the deformation and recovery during the hot rolling are seen in (b), while localized deformation and/or breakup at the dark-etching carbides are evident in (d). 


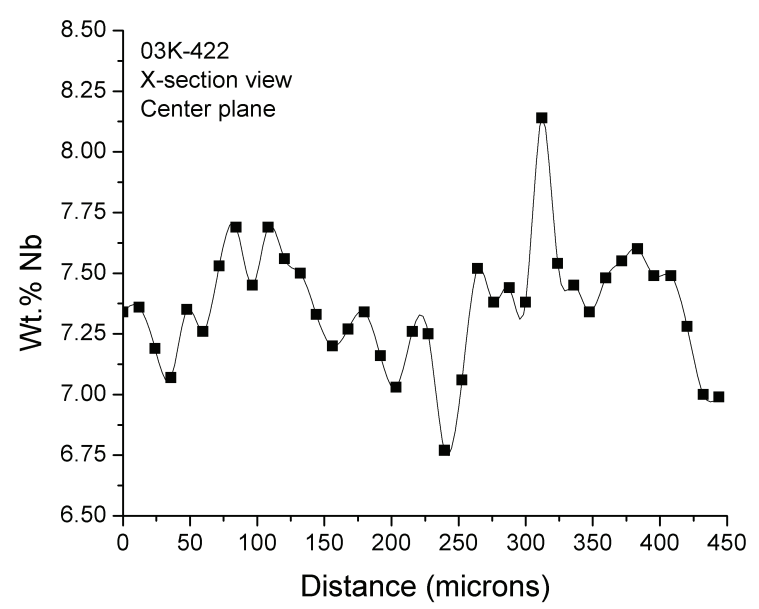

(a)

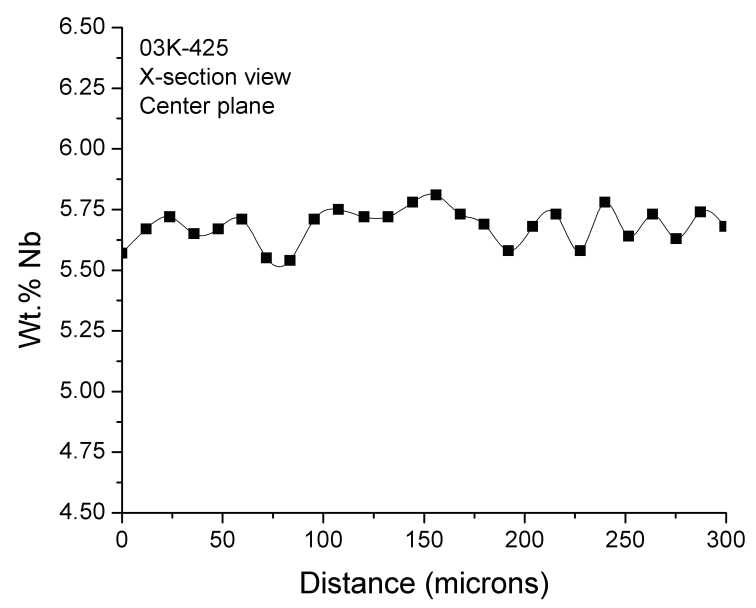

(c)

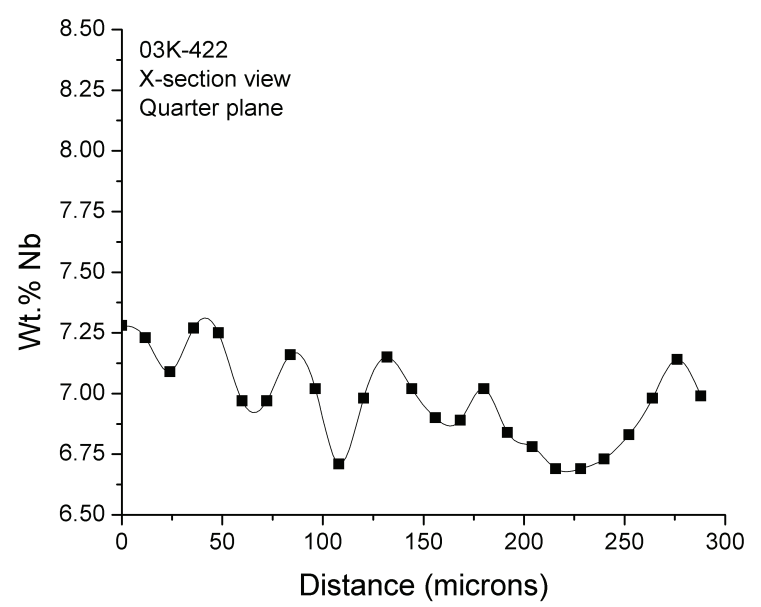

(b)

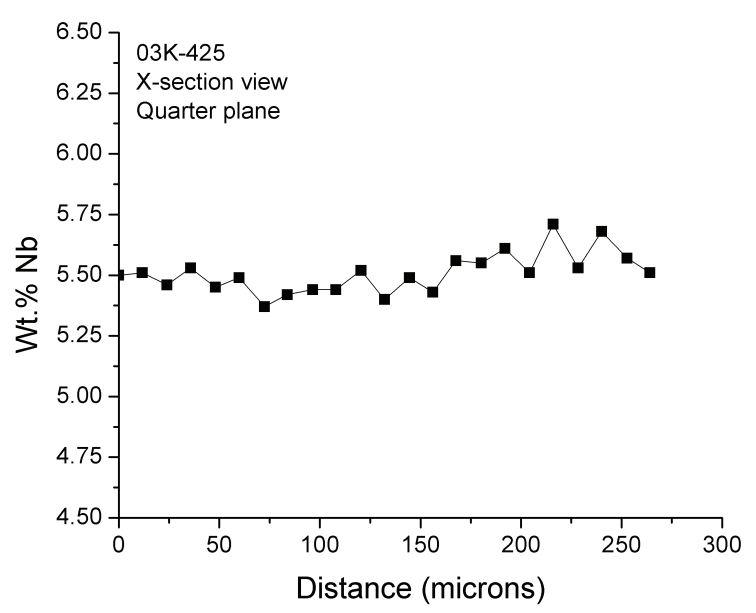

(d)

Figure 9. Post-rolling microprobe traces of 03K-422 (a, b) and 03K-424 (c, d). The coring is significantly reduced in amplitude relative to as-cast. Note that the vertical scales here are magnified six times relative to those given for the as-cast microprobe plots in Figure 7.

Figure 13 reveals the pattern of macrosegregation across the entire plate cross-section, with the highest $\mathrm{Nb}$ content in the center and the lowest on the faces. Unlike the $0.1-1 \mathrm{~mm}$ scale banding characteristic of WR or pictureframe U-6Nb, the macrosegregation in this plate showed only one maximum (and a flattened one at that). The geometry of the aging specimens allows them to be taken from within the center $50 \%$ of the cross-section where the $\mathrm{Nb}$ is the most spatially uniform (which lies inside the quarter plane lines shown in Figure 2). The tensile gage sections ( 0.1 -in. diameter) and the dilatometer specimens $(3 \mathrm{~mm}=0.12$-in. diameter) were deliberately machined out of this center region, and likewise the examination of metallographic specimens by LOM, HV, TEM and XRD focused only on the homogeneous areas in the 0.1 -in. thick zone in the center of the plate. Therefore, these plates are considered nonbanded for all practical purposes when dealing with specimens smaller than the full cross-section. 


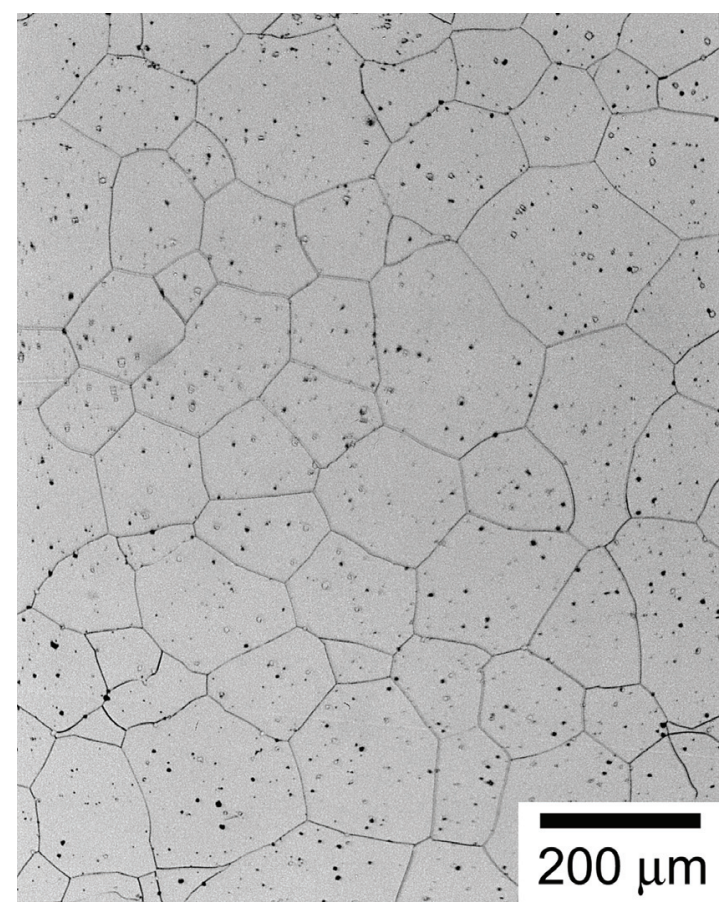

(a)

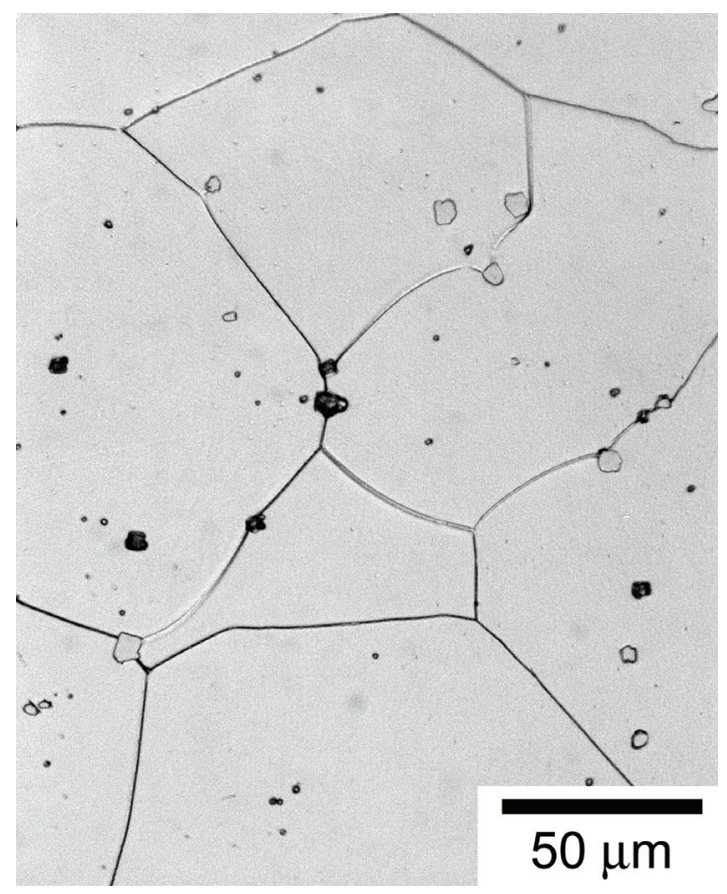

(c)

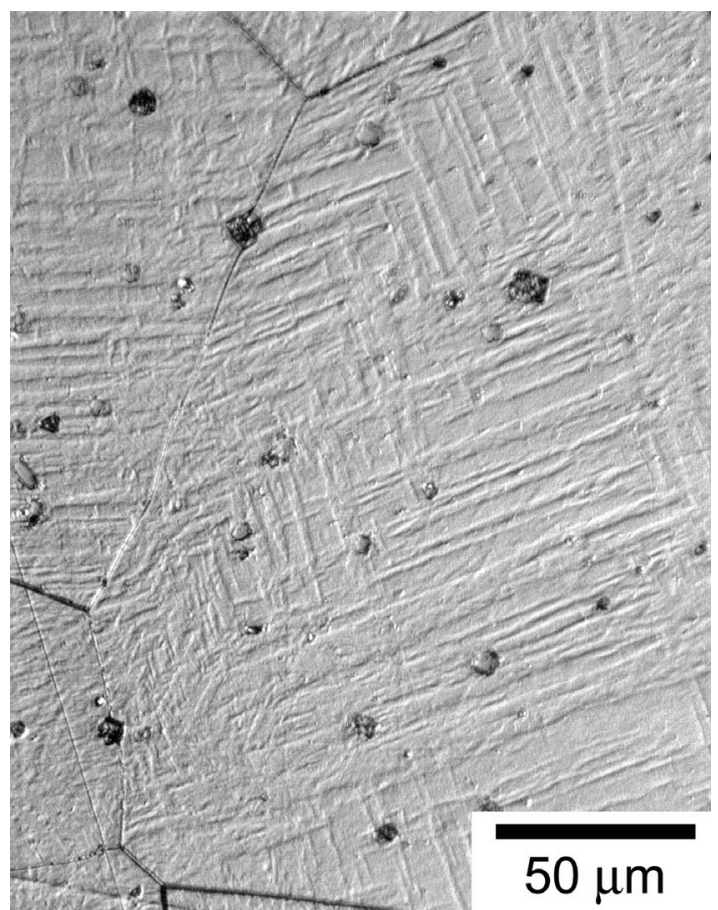

(b)

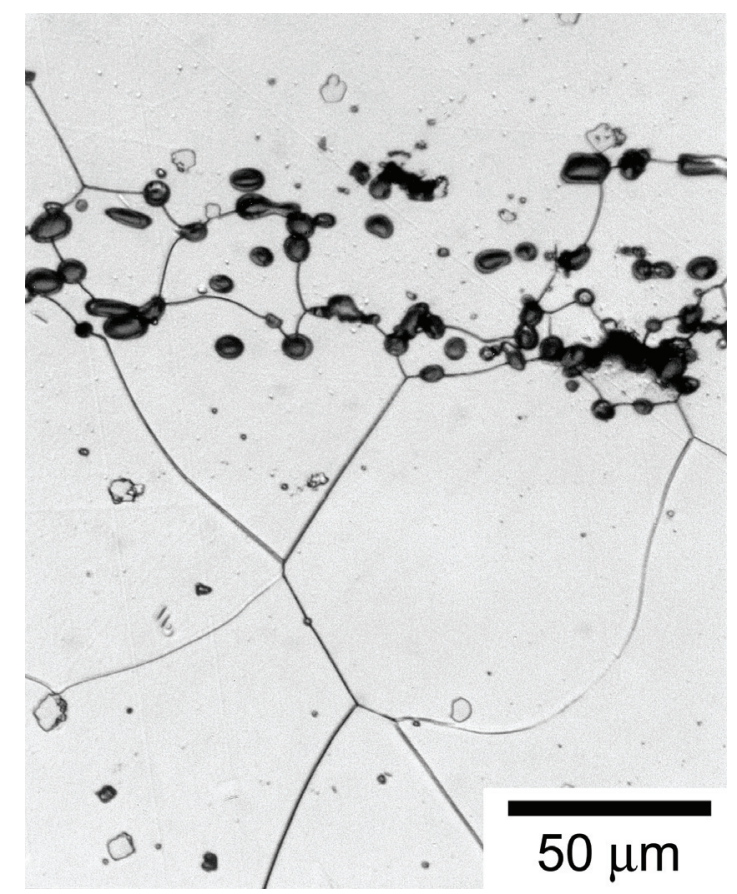

(d)

Figure 10. Optical micrographs showing $03 \mathrm{~K}-422$ after $1,000^{\circ} \mathrm{C}-6$-hour homogenization and water quench. The microstructure consists of roughly equiaxed 200 micron grains (a) in which the $\gamma^{\circ}$ martensitic twin structure is visible (b). It has many $\mathrm{UC}$ and $\mathrm{Nb}_{2} \mathrm{C}$ inclusions, usually distributed as in (c) but with occasional areas of high local density, as in (d). (b) is DIC. The $\mathrm{Nb}_{2} \mathrm{C}$ inclusions are all light-etching in (c) and (d). 


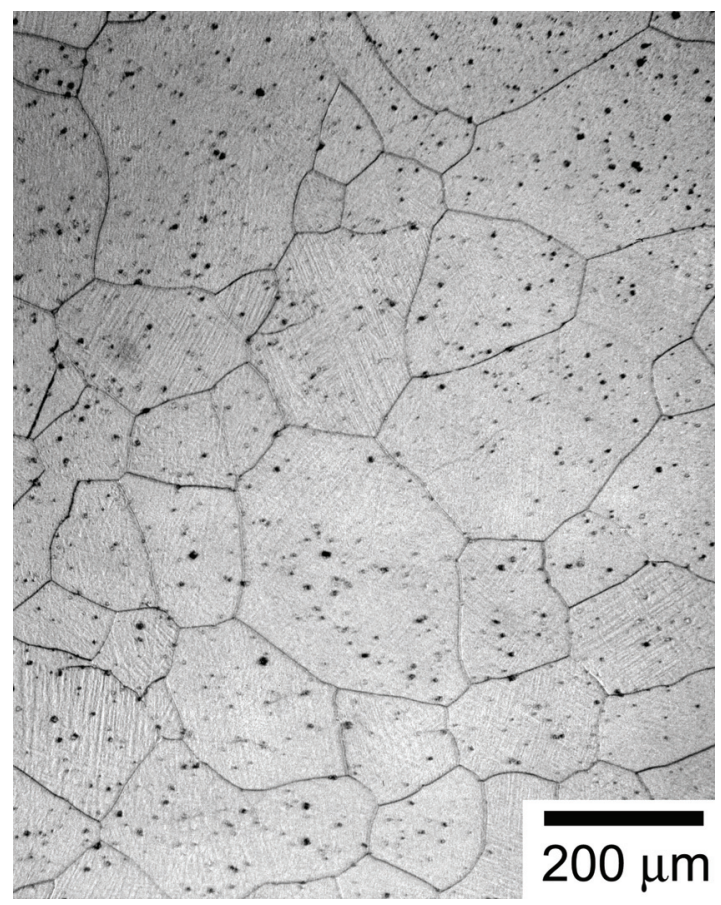

(a)

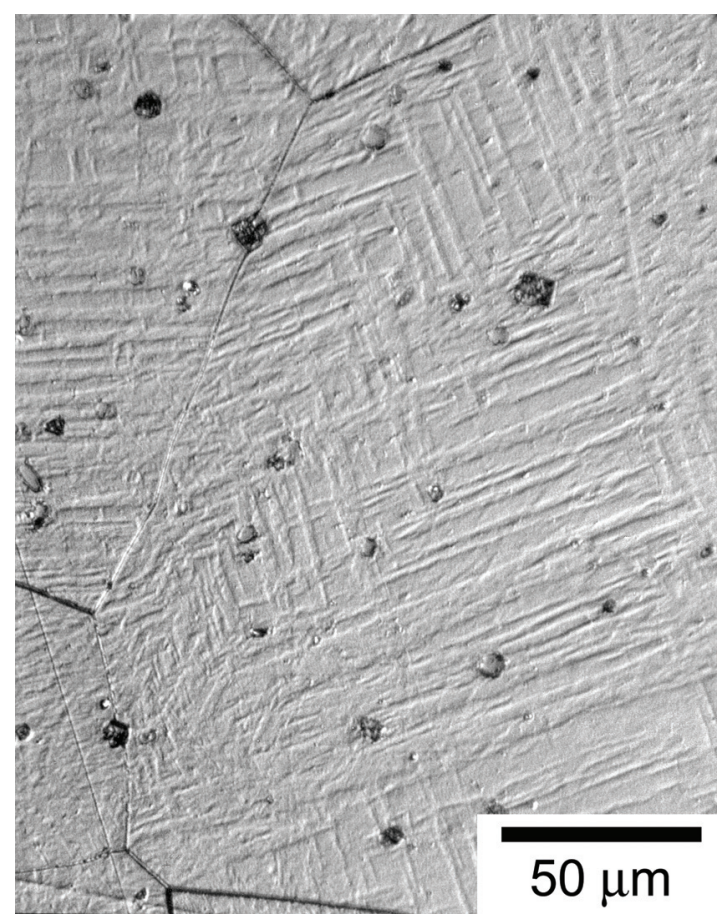

(c)

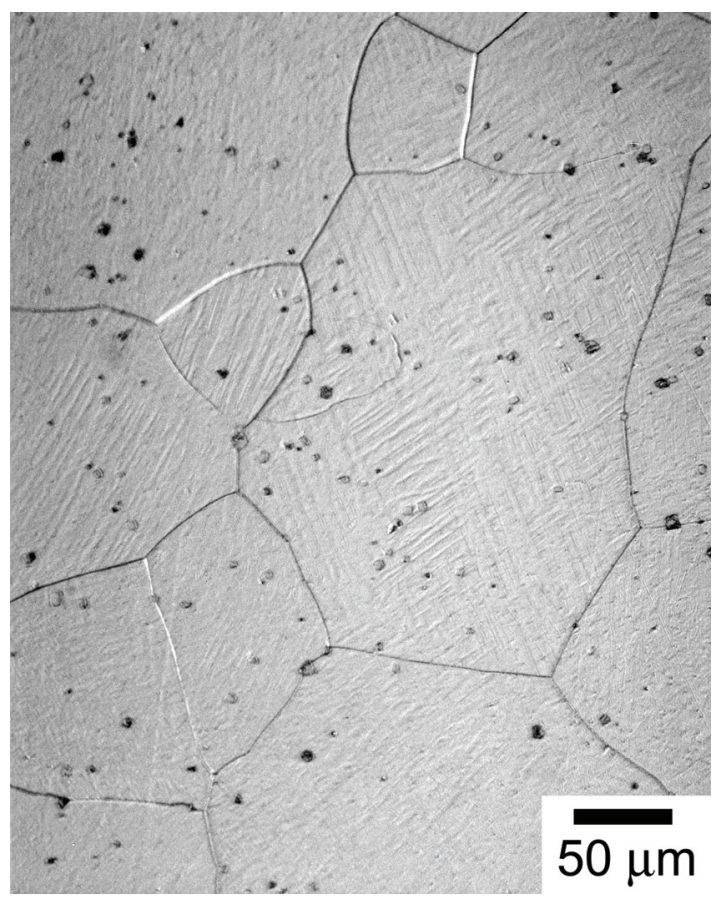

(b)

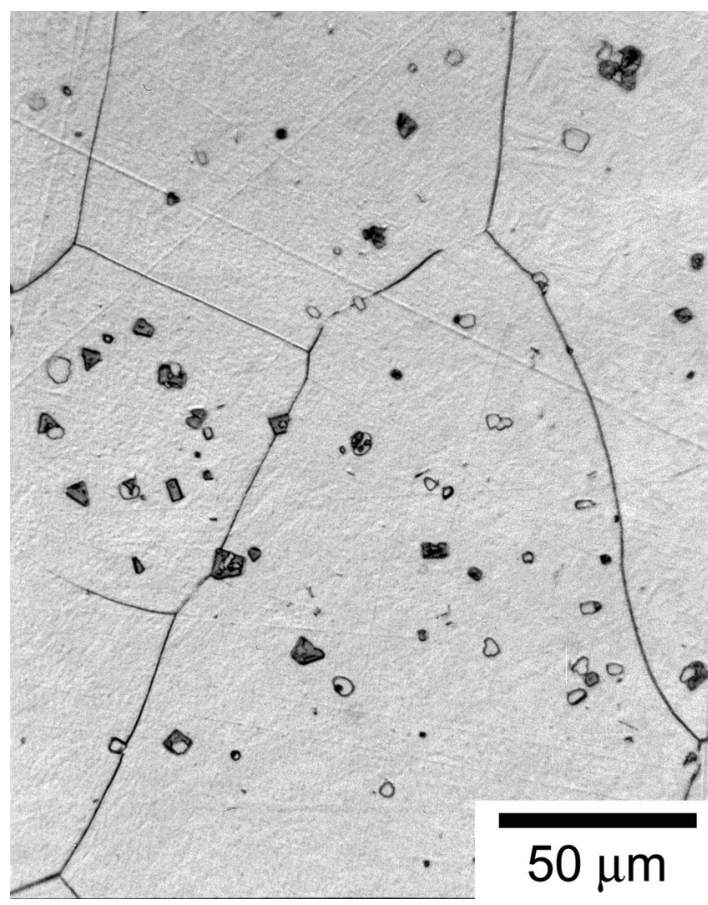

(d)

Figure 11. Optical micrographs showing $03 \mathrm{~K}-425$ after $1,000^{\circ} \mathrm{C}-6$-hour homogenization and water quench. The microstructure consists of roughly equiaxed 200 micron grains (a) in which the $\alpha^{\prime \prime}$ martensitic twin structure is visible $(b, c)$. It has many $\mathrm{UC}$ and $\mathrm{Nb}_{2} \mathrm{C}$ inclusions, usually distributed as in (c) but with occasional areas of high local density, as in (d). (b) and (c) are DIC. 


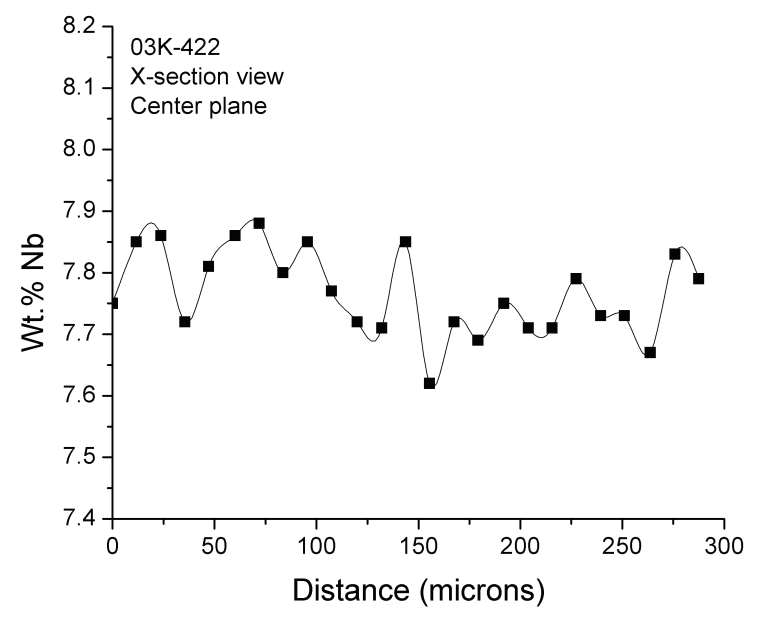

(a)

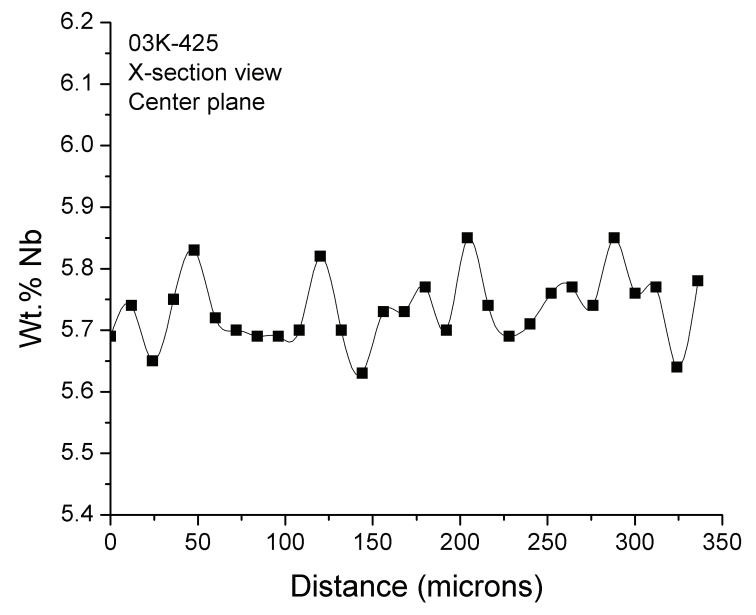

(c)

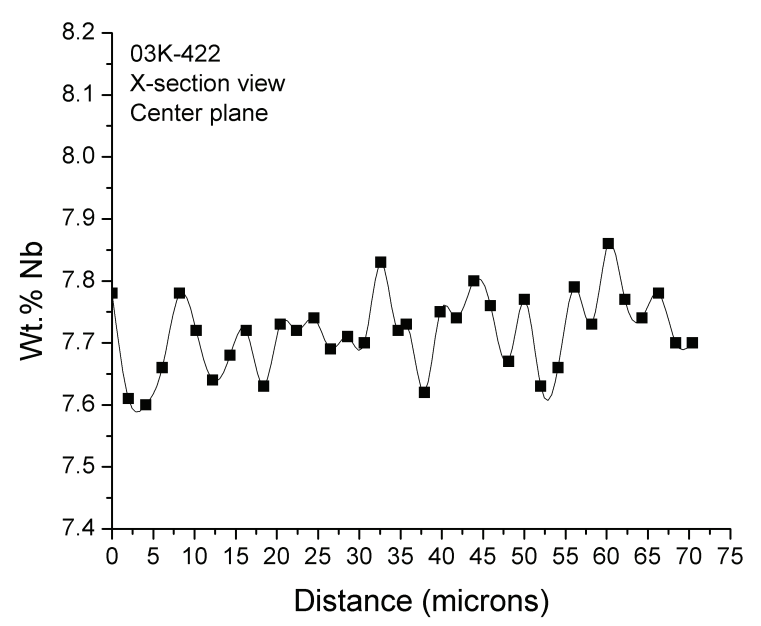

(b)

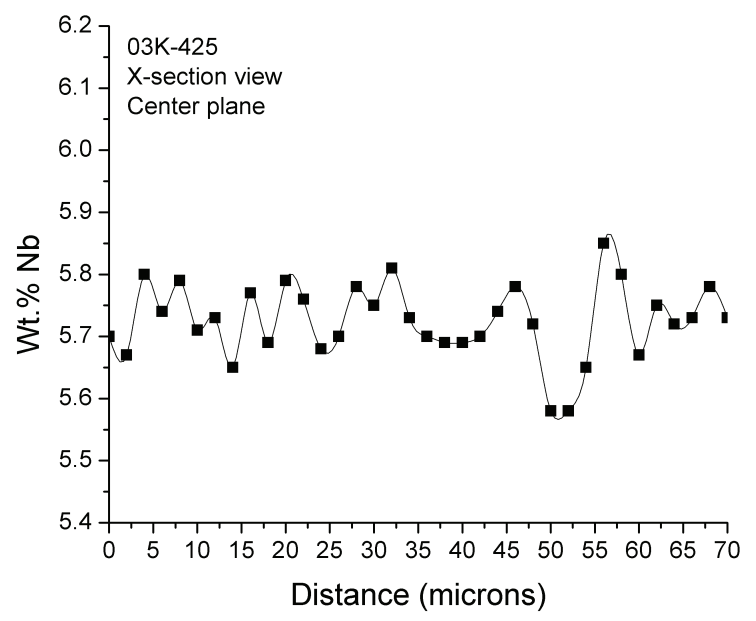

(d)

Figure 12. As-homogenized microprobe traces of 03K-422 (a, b) and 03K-425 (c, d) at coarse $(a, c)$ and fine $(b, d)$ scales. The typical $N b$ variation is less than $\pm 0.1 \mathrm{wt} \%$ about the local mean. Note that the vertical scales here are magnified 3.75 times relative to those given for the as-rolled microprobe plots in Figure 9.

Table 4 provides the chemical analysis results for the four plates. The hydrogen levels quoted pertain only to specimens that underwent the full processing route. Results from specimens analyzed in the as-rolled condition were excluded because their higher hydrogen levels ( $\sim 7 \mathrm{wppm}$ for $03 \mathrm{~K}-422$ and $\sim 5 \mathrm{wppm}$ for $03 \mathrm{~K}-425$ ) were likely due to the fact that as-rolled material did not experience a $1,000^{\circ} \mathrm{C}-6$-hour anneal in a $\sim 3$-micron $\mathrm{Hg}$ vacuum furnace. The principal nonmetallic impurities are $\mathrm{O}, \mathrm{C}$, and $\mathrm{N}$. The principal metallic impurities are $\mathrm{Fe}, \mathrm{B}$, and $\mathrm{Ta}$; $\mathrm{Si}$ and $\mathrm{Ca}$ are not reported but might also be significant. All of these major impurities are commonly found in DU and here are present at reasonably low levels, whereas Ta likely originated in the $\mathrm{Nb}$ addition to the starting $\mathrm{U}-\mathrm{Nb}$ alloy. 


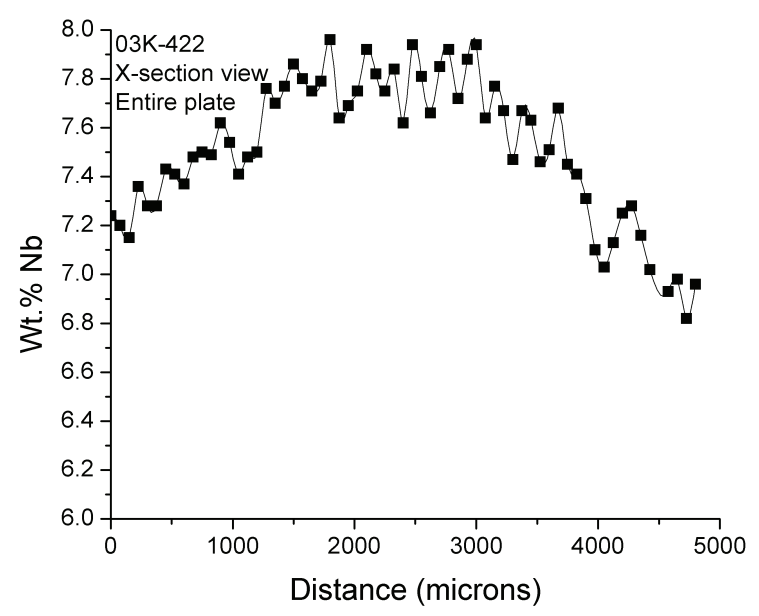

(a)

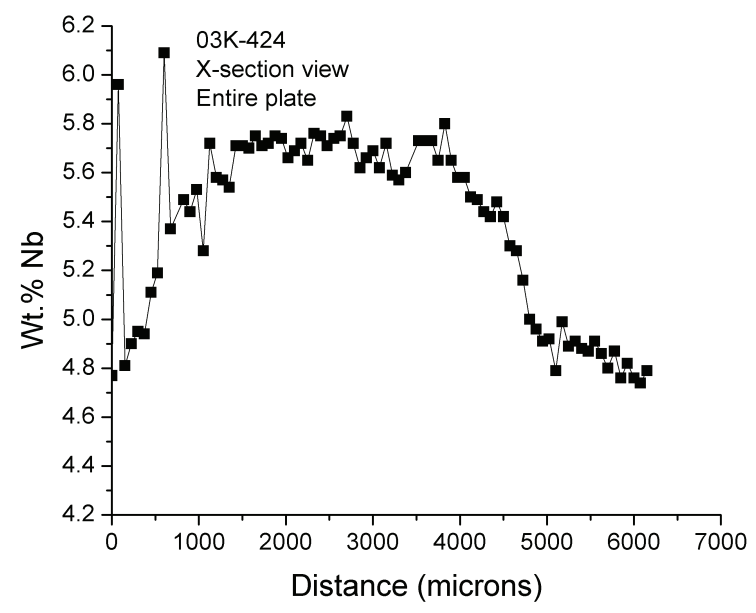

(c)

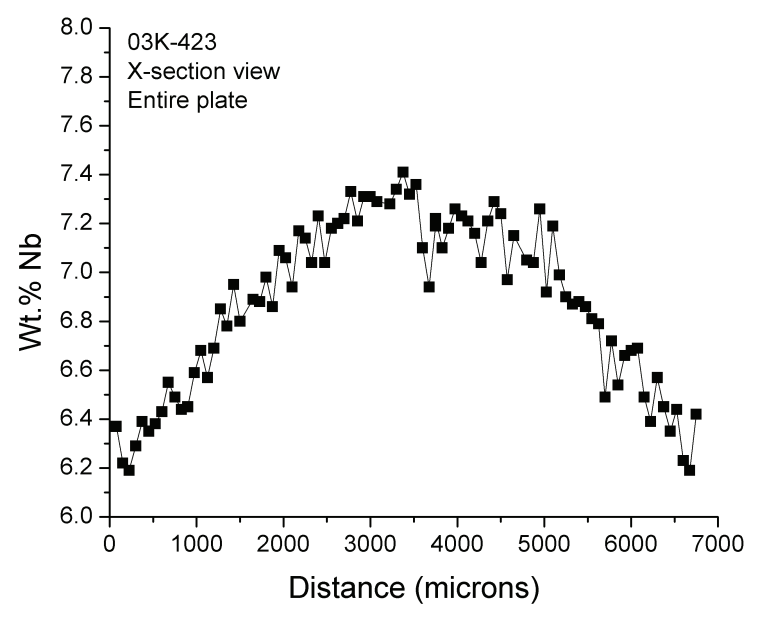

(b)

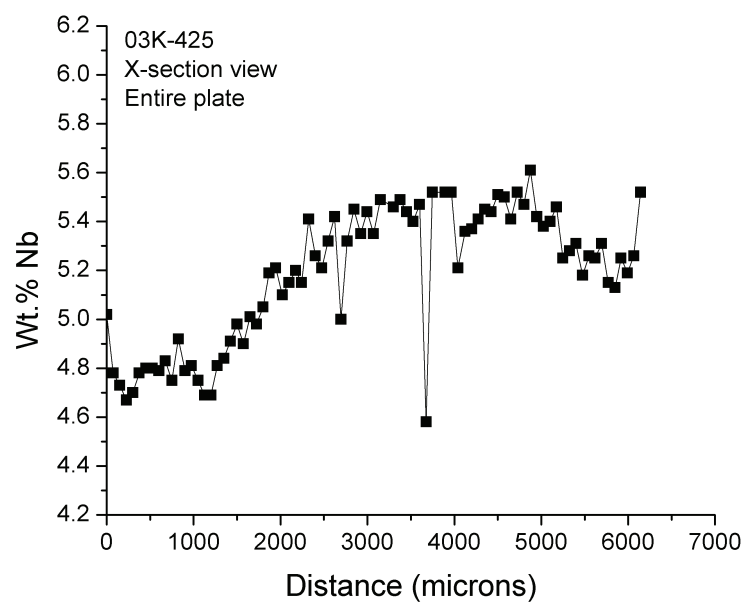

(d)

Figure 13. Global microprobe trace across the entire cross-section of the four as-homogenized plates. Macrosegregation is observed at the scale of the plate thickness, with the Nb at a minimum near the plate faces and at a maximum in the center. The center region from which tensile gage sections (0.1 in. = 2,540 microns diameter) were taken is fairly homogeneous.

The only statistically significant difference in elemental content between the center $50 \%$ and the outer $25 \%$ of the plate cross-section was for $\mathrm{Nb}$, as expected from the microprobe results in Figure 13. Comparison of the $\mathrm{Nb}$ compositions in these two areas measured by ICPMS and EPMA (Table 1) show good agreement. (The EPMA results were derived from the hundreds of points measured in the area of interest.) 
Table 4. Chemical analysis results from the four U-Nb plates, in weight parts per million (wppm). Techniques are described in section 3.2. The standard deviation is from multiple measurements.

\begin{tabular}{|c|c|c|c|c|c|c|c|c|}
\hline \multirow{2}{*}{\begin{tabular}{|l} 
Plate ID \\
Element
\end{tabular}} & \multicolumn{2}{|c|}{$03 K-422$} & \multicolumn{2}{|c|}{$03 K-423$} & \multicolumn{2}{|c|}{$03 K-424$} & \multicolumn{2}{|c|}{$03 K-425$} \\
\hline & Average & StDev & Average & StDev & Average & StDev & Average & StDev \\
\hline $\mathrm{H}$ & 2.35 & 0.42 & & & & & 1.50 & 0.80 \\
\hline B & 48.33 & 30.01 & 131.00 & 14.12 & 50.74 & 19.93 & 81.28 & 26.14 \\
\hline $\mathrm{C}$ & 88.94 & 33.06 & 154.50 & 153.84 & 132.91 & 53.98 & 150.31 & 30.23 \\
\hline $\mathrm{N}$ & 13.33 & 4.01 & 8.32 & 3.27 & 10.88 & 4.45 & 19.99 & 7.42 \\
\hline $\mathrm{O}$ & 76.05 & 32.75 & 48.40 & 15.41 & 38.48 & 10.62 & 40.94 & 21.94 \\
\hline $\mathrm{Mg}$ & 33.87 & 12.08 & & & 2.84 & 1.65 & 3.19 & 0.77 \\
\hline $\mathrm{Al}$ & 50.91 & 23.64 & 24.97 & 25.58 & 19.73 & 5.58 & 43.22 & 9.80 \\
\hline $\mathrm{P}$ & $<1000$ & & & & & & & \\
\hline S & $<5$ & & $<5$ & & $<5$ & & $<5$ & \\
\hline K & $<50$ & & & & & & & \\
\hline $\mathrm{Ti}$ & 16.26 & 5.20 & 5.63 & 0.74 & 10.79 & 0.27 & 8.84 & 2.46 \\
\hline V & 20.33 & 6.82 & & & 4.43 & 0.66 & 7.63 & 2.99 \\
\hline $\mathrm{Cr}$ & $<4.2$ & & & & $<3.6$ & & $<4.3$ & \\
\hline $\mathrm{Mn}$ & 6.05 & 1.26 & 5.33 & 0.38 & 4.21 & 0.23 & 7.79 & 0.53 \\
\hline $\mathrm{Fe}$ & 38.93 & 13.84 & 36.20 & 2.19 & 52.86 & 4.80 & 46.84 & 3.40 \\
\hline Co & $<2.1$ & & & & $<0.06$ & & $<0.06$ & \\
\hline $\mathrm{Ni}$ & 10.13 & 0.82 & 9.50 & 0.62 & 11.75 & 0.45 & 11.52 & 0.48 \\
\hline $\mathrm{Cu}$ & 20.23 & 27.78 & 12.47 & 0.46 & 7.70 & 0.26 & 8.30 & 0.75 \\
\hline $\mathrm{Zn}$ & 16.91 & 5.22 & & & & & & \\
\hline $\mathrm{Ga}$ & 0.64 & 0.31 & & & & & & \\
\hline As & 4.60 & 2.06 & & & & & & \\
\hline $\mathrm{Rb}$ & $<8$ & & & & & & & \\
\hline $\mathrm{Sr}$ & 6.49 & 2.20 & & & & & & \\
\hline Y & 12.61 & 10.17 & 0.51 & 0.42 & 4.90 & 1.95 & 5.32 & 3.70 \\
\hline
\end{tabular}




\begin{tabular}{|c|c|c|c|c|c|c|c|c|}
\hline Plate ID & \multicolumn{2}{|c|}{$03 K-422$} & \multicolumn{2}{|c|}{$03 K-423$} & \multicolumn{2}{|c|}{$03 K-424$} & \multicolumn{2}{|c|}{$03 K-425$} \\
\hline Element & Average & StDev & Average & StDev & Average & StDev & Average & StDev \\
\hline $\mathrm{Zr}$ & 15.97 & 3.22 & 11.85 & 0.76 & 23.35 & 1.16 & 11.04 & 0.96 \\
\hline $\mathrm{Nb}$-center & 76909.09 & 3278.55 & 74638.00 & 1158.00 & 59475.00 & 805.71 & 56000.00 & 5626.90 \\
\hline $\mathrm{Nb}$-outside & 69300.00 & 1009.95 & 67850.00 & 6912.24 & 54275.00 & 537.74 & 53900.00 & 1131.37 \\
\hline Mo & 3.38 & 0.22 & 3.27 & 0.13 & 2.60 & 0.12 & 1.19 & 0.09 \\
\hline $\mathrm{Ag}$ & $<6$ & & & & & & & \\
\hline $\mathrm{Cd}$ & 13.07 & 1.42 & & & & & & \\
\hline Sn & 9.04 & 8.25 & & & & & & \\
\hline $\mathrm{Sb}$ & 4.44 & 1.59 & & & & & & \\
\hline $\mathrm{Ba}$ & 15.62 & 8.06 & & & & & & \\
\hline $\mathrm{Hf}$ & $<4$ & & 0.35 & 0.11 & $<0.024$ & & $<0.16$ & \\
\hline $\mathrm{Ta}$ & 106.79 & 6.75 & 82.34 & 9.77 & 105.89 & 8.47 & 49.78 & 8.30 \\
\hline W & 9.38 & 0.85 & 46.32 & 3.53 & 7.90 & 0.39 & 7.07 & 0.53 \\
\hline Ir & $<16$ & & $<0.26$ & & $<0.06$ & & & \\
\hline $\mathrm{Pt}$ & $<4.2$ & & 0.04 & 0.03 & $<0.018$ & & $<0.07$ & \\
\hline $\mathrm{Au}$ & 7.94 & 3.33 & 2.82 & 0.79 & $<0.06$ & & $<0.86$ & \\
\hline $\mathrm{Tl}$ & 1.17 & 0.45 & & & & & & \\
\hline Th & $<2.1$ & & 0.35 & 0.18 & $<0.012$ & & $<0.02$ & \\
\hline \multicolumn{9}{|c|}{$\begin{array}{ll}\text { Elements }<4 \text { wppm: } \mathrm{Ge}, \mathrm{Rh}, \mathrm{Tm} & \text { Elements }<1 \text { wppm: } \mathrm{La}, \mathrm{Pb}, \mathrm{Bi} \\
\text { Elements }<2 \text { wppm: } \mathrm{Ru}, \mathrm{Pd}, \mathrm{Cs}, \mathrm{Lu} & \text { Elements qualitatively not detected: } \mathrm{Re} \text {, Os } \\
\text { Elements analyzed but not reported due to quantification difficulties: } \mathrm{Si}, \mathrm{Ca}\end{array}$} \\
\hline
\end{tabular}




\section{PHASE CHARACTERIZATION}

The majority phase observed by XRD was as expected for homogeneous rapidly quenched alloys of these compositions (Anagnostidis et al., 1964, Tangri and Chaudhuri 1965). The single XRD spectrum from $03 \mathrm{~K}-425$ (U-5.6Nb actual), Figure 14, showed only monoclinic $\alpha^{\prime \prime}$, whereas the two spectra from $03 \mathrm{~K}-422$ (U-7.7Nb actual), Figure 15 , showed mostly tetragonal $\gamma^{\circ}$ with a few weight percent of $\alpha^{\prime \prime}$. The Rietveld-refined lattice parameters and unit cell volumes are listed in Table 5. No second phases were observed in the U-5.6 $\mathrm{Nb}$, though it should be noted that the inclusions observed by LOM (in both alloys), principally $\mathrm{Nb}_{2} \mathrm{C}$ and $\mathrm{UC}$, had too small a volume fraction to be observed by this XRD technique. Further details of the challenges encountered during these XRD studies in both as-quenched and aged conditions can be found in (Volz et al., 2006). In particular, it should be noted that at present it is believed that the GSAS fits to these data could be improved in future studies with adequate modeling of microstructural features such as planar defects (i.e., stacking faults and twins). All data within the same composition in the as-quenched and aging studies were refined with a consistent approach, yet the refinements were compromises as the program tried to handle strain broadening and stacking faults within these samples. Further studies are being undertaken to better handle these data and to understand mechanisms operating at the atomistic level through other techniques.

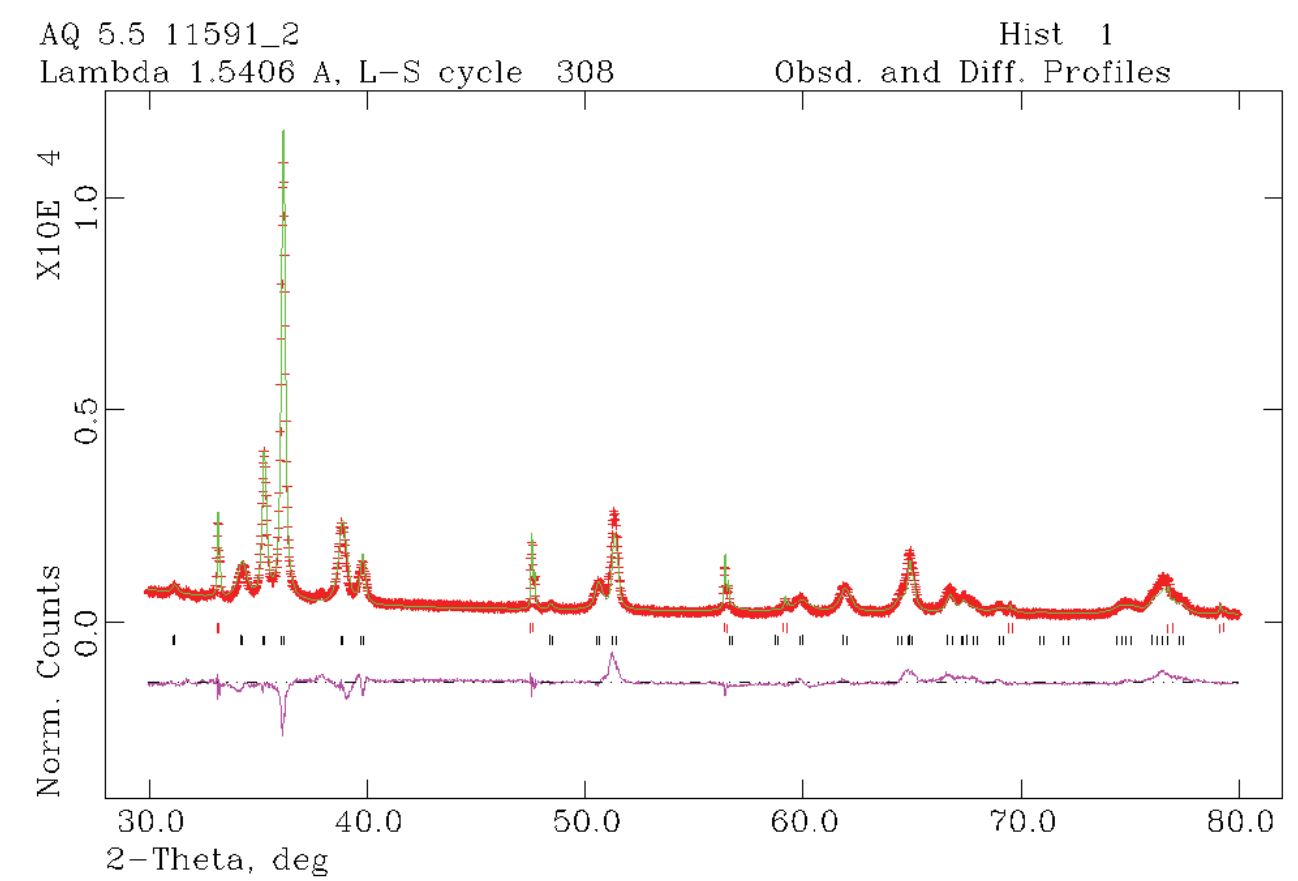

Figure 14. X-ray diffraction scan of as-quenched $U-5.6 N b$ (03K-425). Experimental data points are red, the refined Rietveld fit is green, and the difference between the data and fit is pink (below). Tick marks delineate peak positions for the two phases: $\alpha^{\prime \prime}$ (black) and $\mathrm{CeO}_{2}$ standard (red). 


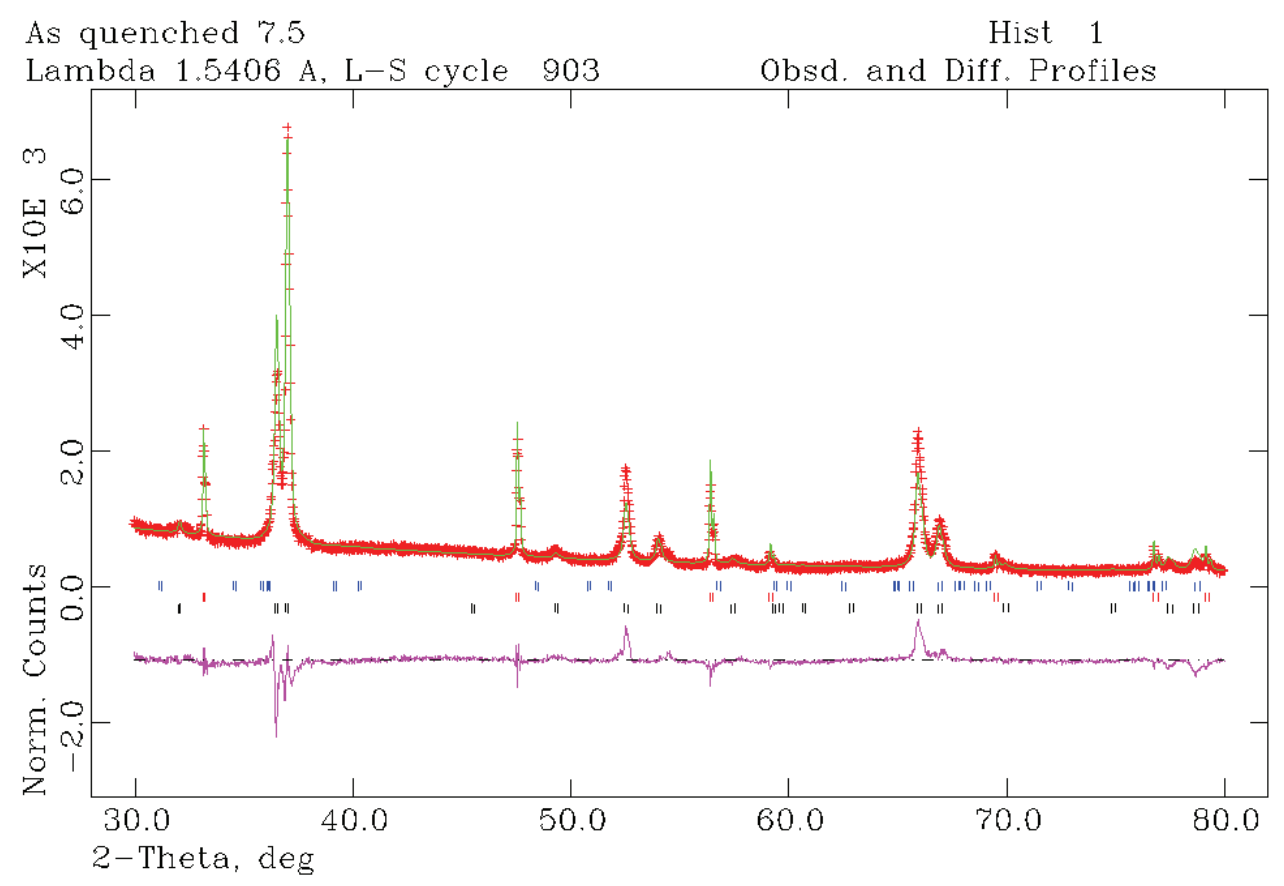

(a)

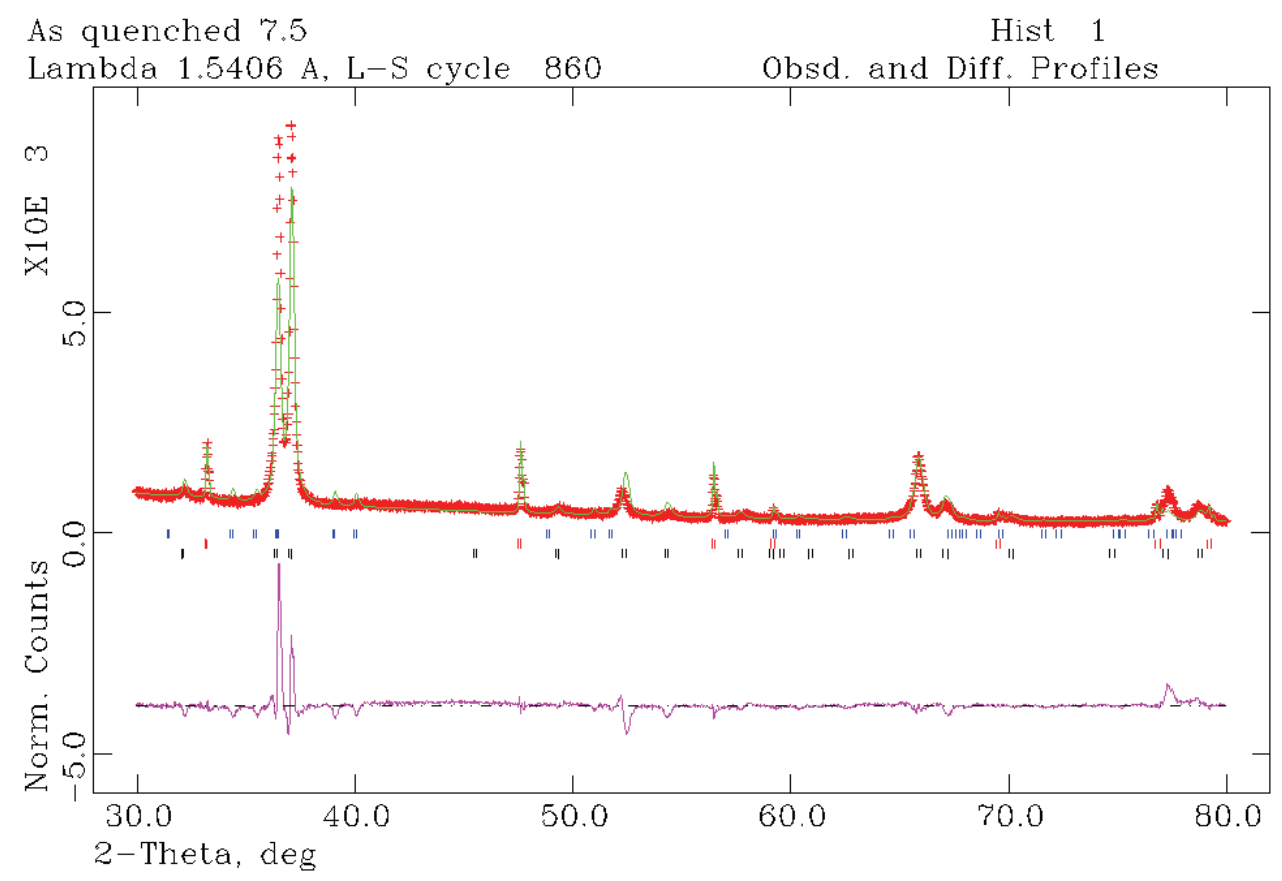

(b)

Figure 15. X-ray diffraction scan of two different samples of as-quenched $U-7.7 N b(03 K-422)$. Experimental data points are red, the refined Rietveld fit is green, and the difference between the data and fit is pink (below). Tick marks delineate peak positions for the phases: $\gamma^{\circ}$ (black), $\mathrm{CeO}_{2}$ standard (red) and $\alpha^{\prime \prime}$ (blue). 


\begin{tabular}{|c|c|c|c|c|c|c|c|c|}
\hline Alloy & $\begin{array}{c}\text { MST-6 } \\
\text { Job \# }\end{array}$ & Phase & a (Á) & b (Á) & c (Á) & $\begin{array}{c}\gamma \\
\text { (Degrees) }\end{array}$ & $\begin{array}{c}\text { Unit Cell } \\
\text { Volume }\left(\AA^{3}\right)\end{array}$ & c/a Ratio \\
\hline $\mathrm{U}-5.6 \mathrm{Nb}$ & $11591-2$ & $\alpha^{\prime \prime}$ & $\begin{array}{r}2.8961 \\
\pm 0.0004\end{array}$ & $\begin{array}{r}5.7537 \\
\pm 0.0012\end{array}$ & $\begin{array}{r}4.9782 \\
\pm 0.0007\end{array}$ & $\begin{array}{l}92.038 \\
\pm 0.014\end{array}$ & $\begin{array}{l}82.900 \\
\pm 0.017\end{array}$ & \\
\hline $\begin{array}{l}\mathrm{U}-7.7 \mathrm{Nb} \\
(\# 1)\end{array}$ & 11519-1 & $\gamma^{\circ}$ & $\begin{array}{r}4.9306 \\
\pm 0.0004\end{array}$ & & $\begin{array}{r}3.3971 \\
\pm 0.0004\end{array}$ & & $\begin{array}{l}82.585 \\
\pm 0.014\end{array}$ & $\begin{array}{r}0.6890 \\
\pm 0.0001\end{array}$ \\
\hline $\begin{array}{l}\mathrm{U}-7 . \mathrm{Nb} \\
(\# 2)\end{array}$ & $11519-2$ & $\gamma^{\circ}$ & $\begin{array}{r}4.9455 \\
\pm 0.0006\end{array}$ & & $\begin{array}{r}3.3818 \\
\pm 0.0007\end{array}$ & & $\begin{array}{l}82.711 \\
\pm 0.021\end{array}$ & $\begin{array}{r}0.6838 \\
\pm 0.0002\end{array}$ \\
\hline
\end{tabular}

Rapid induction heating to $925^{\circ} \mathrm{C}$ and subsequent He gas quenching of 3-mm diameter, 10-mm-long specimens in a dilatometer, over multiple cycles, showed martensitic transition signals in $03 \mathrm{~K}-425$ specimens (Figure $16 \mathrm{a}$, run $\mathrm{A}$ ). $\mathrm{A}_{\mathrm{s}}$ and $\mathrm{A}_{\mathrm{f}}$ temperatures for a distinct volume contraction on heating were found to be $175^{\circ} \mathrm{C}$ and $215^{\circ} \mathrm{C}$, respectively, while $\mathrm{M}_{\mathrm{s}}$ and $\mathrm{M}_{\mathrm{f}}$ for a distinct volume expansion on cooling were $160^{\circ} \mathrm{C}$ and $85^{\circ} \mathrm{C}$, respectively. These are characteristic signs of the $\alpha^{\prime \prime} \leftrightarrow \gamma^{\circ}$ transition (Vandermeer et al., 1978). Using correlations derived from an independent data set of transition temperatures in $41 \mathrm{U}-\mathrm{Nb}$ alloys (Hackenberg et al., 2007), the temperatures correspond to an alloy composition of $5.79 \pm 0.06 \mathrm{wt} \% \mathrm{Nb}$ that is within the bounds of the wet chemical analysis results for the center of this alloy $(5.60 \pm 0.56 \mathrm{wt} \% \mathrm{Nb})$. A distinct $\alpha^{\prime \prime} \leftrightarrow \gamma^{\circ}$ martensitic signal was found in only $22 \%$ ( 5 out of 23 ) of the $03 \mathrm{~K}-425$ specimens on which dilatometry was run and the origin of this discrepancy, which is also found in banded $\mathrm{U}-6 \mathrm{Nb}$, is unclear but may relate to the amount of impurity elements (especially oxygen) in the specimen. Regardless of whether a distinct martensite signal was observed or not, the heating and cooling curves were very reproducible when a given specimen was run multiple (typically five) times. It should also be noted that $\mathrm{U}-5.6 \mathrm{Nb}$ exhibited volume changes characteristic of the diffusional formation of cellular product on very slow cooling and the dissolution of this product on subsequent rapid heating (Figure 16a, run B) near the $650^{\circ} \mathrm{C}$ monotectoid temperature (Koike et al., 1998).

This transformation has been noted in other studies (Jackson and Miley 1968; Eckelmeyer 1982). For reference, the temperature-time profiles recorded during the cooling and reheating cycles in runs $A$ and $B$ are provided in Figures $16 \mathrm{~b}-\mathrm{c}$ and $16 \mathrm{~d}-\mathrm{e}$, respectively. 
The $\alpha^{\prime \prime} \leftrightarrow \gamma^{\circ}$ transition is not expected in the nominal U-7.5Nb alloys at/above ambient temperature because trends indicate its $\mathrm{M}_{\mathrm{s}}$ will occur below ambient temperature (if it occurs at all). Figure 17 shows the electrical resistance signal obtained on cryogenic cooling of $03 \mathrm{~K}-422$ $\left(\mathrm{U}-7.7 \mathrm{Nb}\right.$ ) to $4.6 \mathrm{~K}$, which gave no signs of the $\gamma^{\circ} \rightarrow \alpha^{\prime \prime}$ martensitic transition, even though one might expect this to transpire, based on extrapolations of $\mathrm{M}_{\mathrm{s}}$ and $\mathrm{M}_{\mathrm{f}}$ data vs $\mathrm{Nb}$ composition. Although the origin of this unexpected stability of $\gamma^{\circ}$ is unclear, it does not appear to be peculiar to this particular plate because the same measurement done on a specimen taken from a compositionally homogeneous arc-melted and homogenized $\mathrm{U}-7.75 \mathrm{Nb}$ alloy likewise failed to show a signal for the $\alpha^{\prime \prime} \leftrightarrow \gamma^{\circ}$ transition when starting from the same as-solutionized-andquenched condition.

Signals for the $\gamma^{\circ} \leftrightarrow \gamma$ transition in both 03K-425 (Figure 16a) or 03K-422 (results not shown here) were too faint to derive accurate transition temperatures, especially in cases of multiple faint signals. This is likely due to the very small volume change attending this transition. Slow cooling at rates as low as $0.21 \mathrm{~K} / \mathrm{s}$ (and subsequent fast reheating) failed to produce any dilatation signal for the diffusional cellular decomposition reaction in $\mathrm{U}-7.7 \mathrm{Nb}$ (03K-422). Further work at even slower cooling rates (e.g., $0.05 \mathrm{~K} / \mathrm{s}$ ) will be required to observe such a signal.

Combined with the EPMA and LOM results from the as-homogenized and quenched specimens, these XRD and dilatometry results verify that the finished plate microstructure (after it is resolutionized and quenched) consists of compositionally homogeneous, single phase $\alpha^{\prime \prime}$ in U-5.6 Nb $(03 \mathrm{~K}-425)$ and $\sim 95 \mathrm{wt} \% \gamma^{\circ} \mathrm{U}-7.7 \mathrm{Nb}(03 \mathrm{~K}-422)$. This is the desired starting microstructure before the start of low-temperature aging experiments described elsewhere (Hackenberg et al., 2007; Volz et al., 2006).

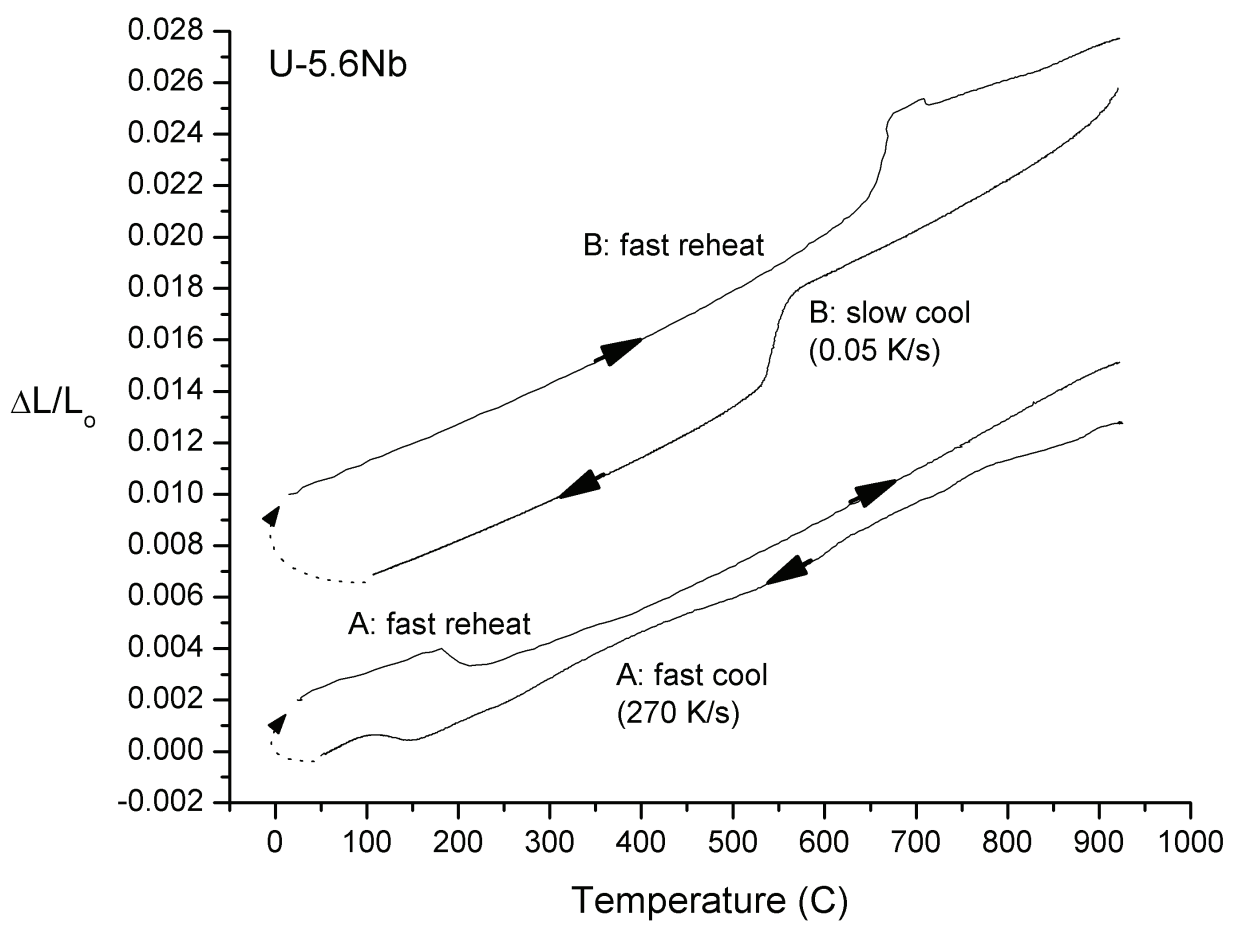

Figure 16. (a) 


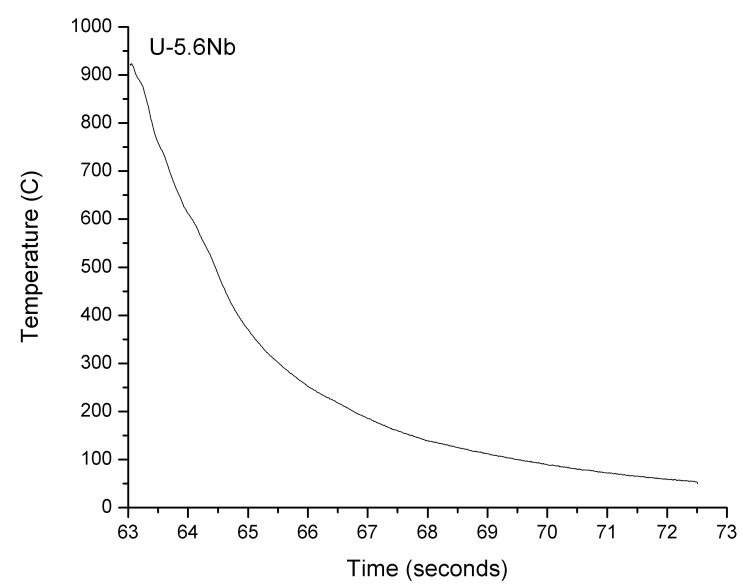

(b)

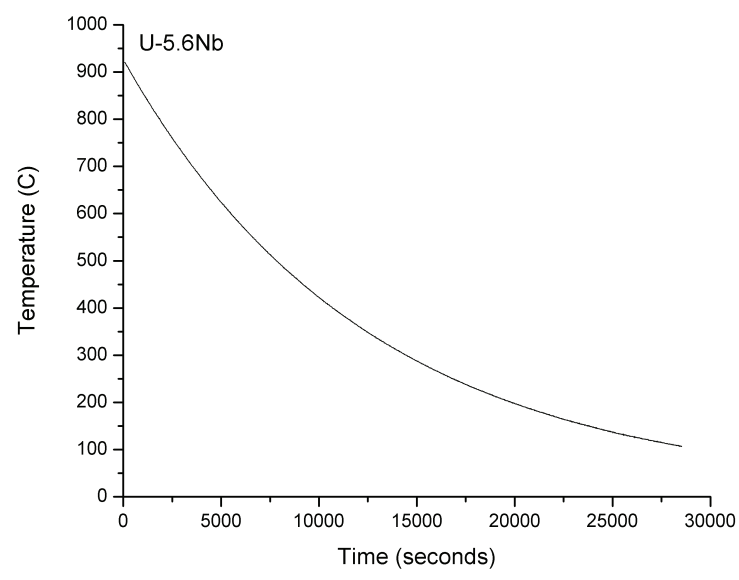

(d)

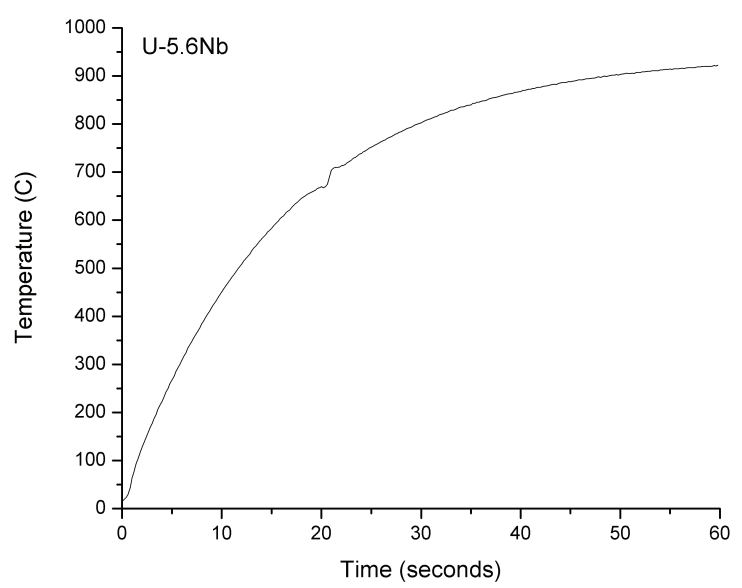

(c)

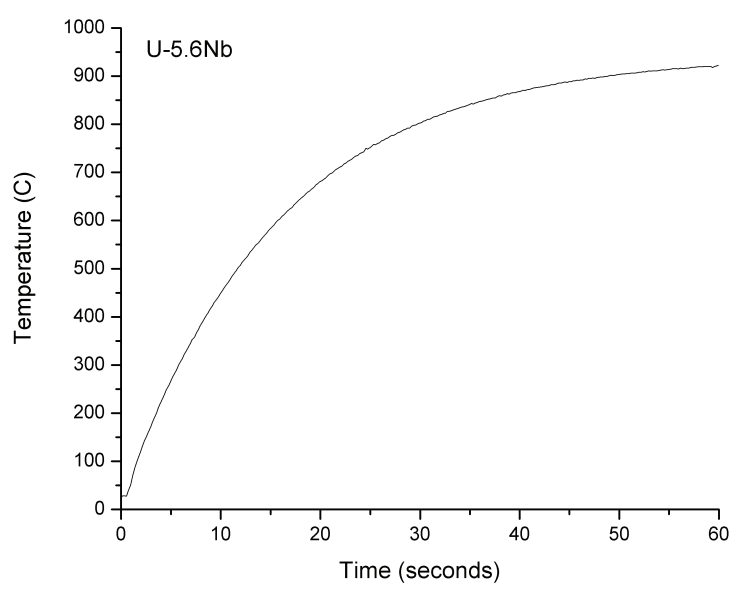

(e)

Figure 16. Dilatometry of $U-5.6 \mathrm{Nb}(03 \mathrm{~K}-425)$. (a) Dilatation curves for two different coolingreheat paths (indicated by the arrows): Run $A$ highlights the diffusionless $\gamma^{\circ} \leftrightarrow \alpha^{\prime \prime}$ martensitic transition in the $50^{\circ} \mathrm{C}-200^{\circ} \mathrm{C}$ range during fast cooling (b) and subsequent reheating (c), with a positive volume change observed on cooling and the opposite on reheating. Run $B$ highlights the diffusional reactions in the $500^{\circ} \mathrm{C}-700^{\circ} \mathrm{C}$ range that form a cellular product with negative volume change on slow cooling (d) and subsequently dissolve back to gamma with positive volume change on fast reheating (e). The cooling rates indicated on the Figure are the average between $700^{\circ} \mathrm{C}$ and $600^{\circ} \mathrm{C}$. The dilatation curves are offset from one another for clarity. The relevant temperature-time profiles for run $A$ are given in (b) and (c), while those for run $B$ are given in (d) and (e). 


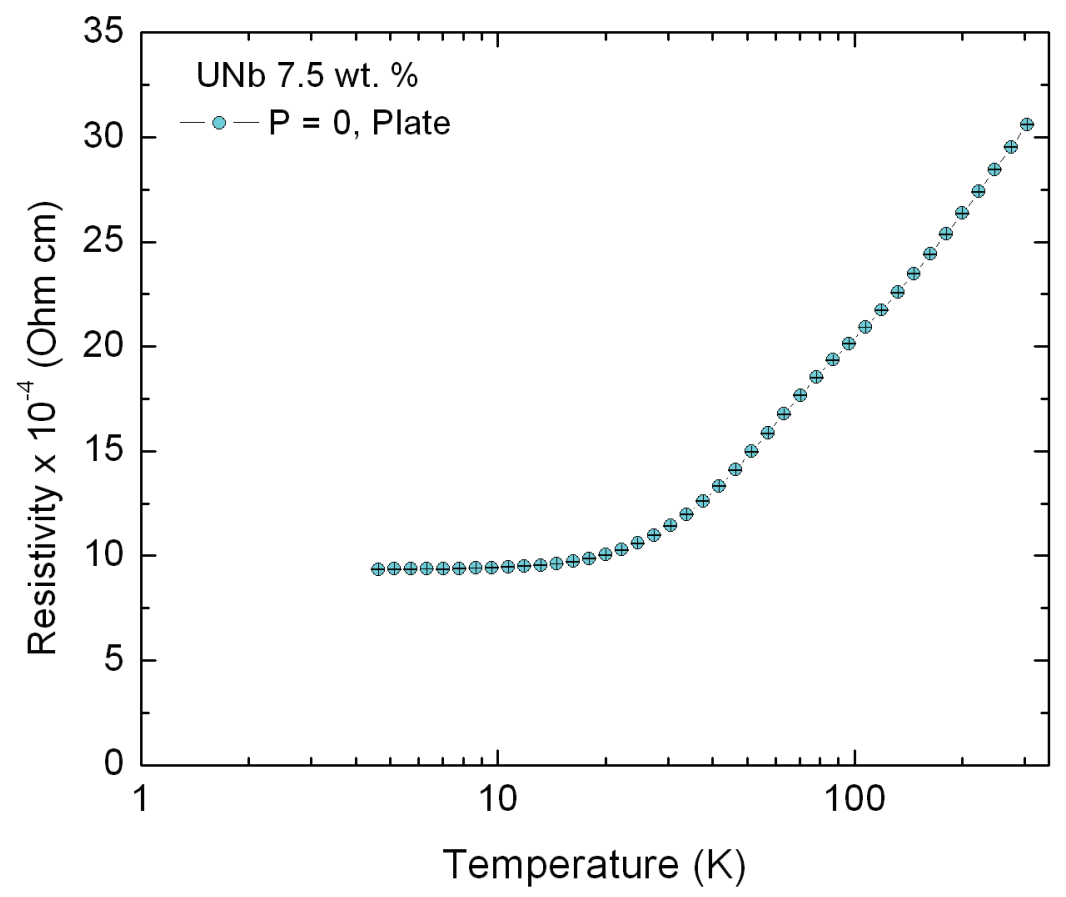

Figure 17. Electrical resistivity during subambient cooling of $03 \mathrm{~K}-422(\mathrm{U}-7.7 \mathrm{Nb}$ actual). The specimen was previously quenched from an $850^{\circ} \mathrm{C}$ solution anneal to provide the starting martensitic $\gamma^{\rho}$ structure. Although the temperature range for the $\gamma^{\rho} \rightarrow \alpha^{\prime \prime}$ martensitic transition extrapolates to 120-150 K, no signs of this were observed. Note that the temperature is on a log scale.

\section{PROPERTY CHARACTERIZATION}

Figure 18 shows the tensile response from U-5.6Nb (03K-425) and U-7.7Nb (03K-422). Some variability in the post-first-yield response are observed, which gives rise to variability in the second yield stress, ultimate tensile stress, and elongations. Data taken from tensile testing pictureframe (banded) $\mathrm{U}-6 \mathrm{Nb}$, in the same specimen geometry, are also shown for comparison. The strength, modulus and ductility data are provided in Table 6 along with standard deviations that provide a measure of the property spread. Fractographs from a subset of these specimens appear in Figure 19. All three alloys show signs of a ductile microvoid growth and coalescence failure mechanism. In general, the two nonbanded alloys show more inclusions associated with the microvoids than the banded $\mathrm{U}-6 \mathrm{Nb}$, with the U-7.7Nb having deeper microvoids than U-5.6 $\mathrm{Nb}$, consistent with their differences in total plastic elongation to failure and percent reduction in area (\%RA). It is unclear why the nonbanded plates have a significantly higher spread in properties than the banded U-6Nb, though it may be related to the greater degree of hot working (forging) experienced by the banded $\mathrm{U}-6 \mathrm{Nb}$ during processing. 


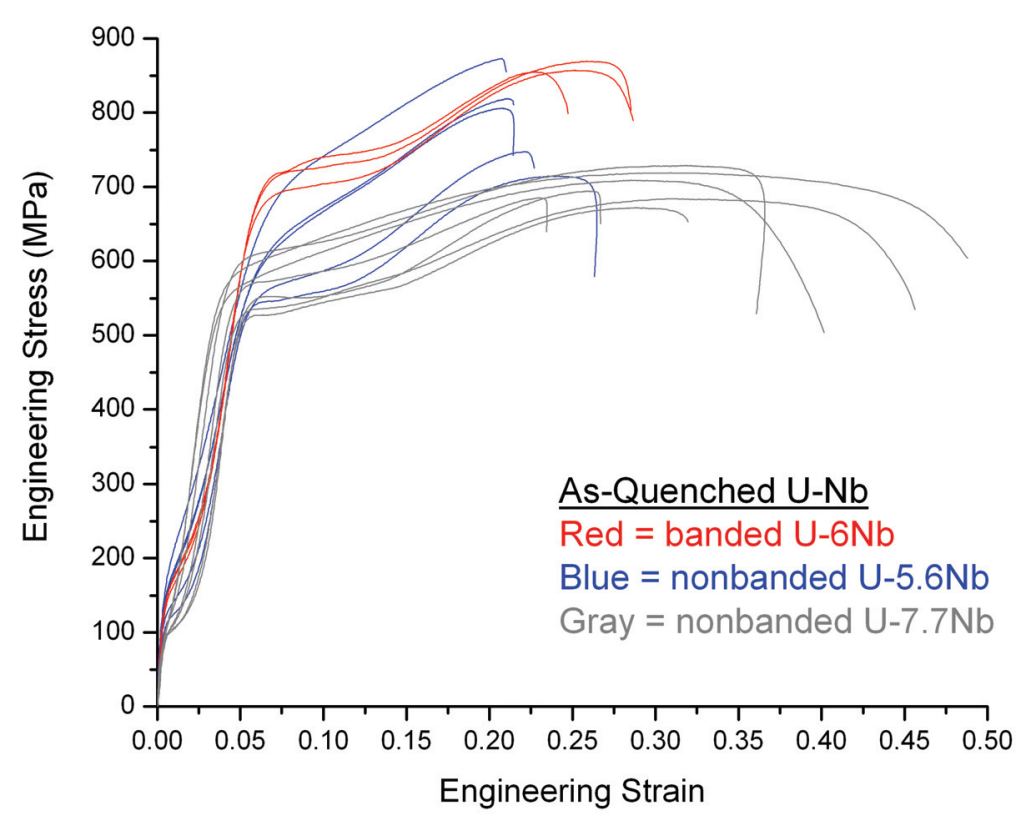

(a)

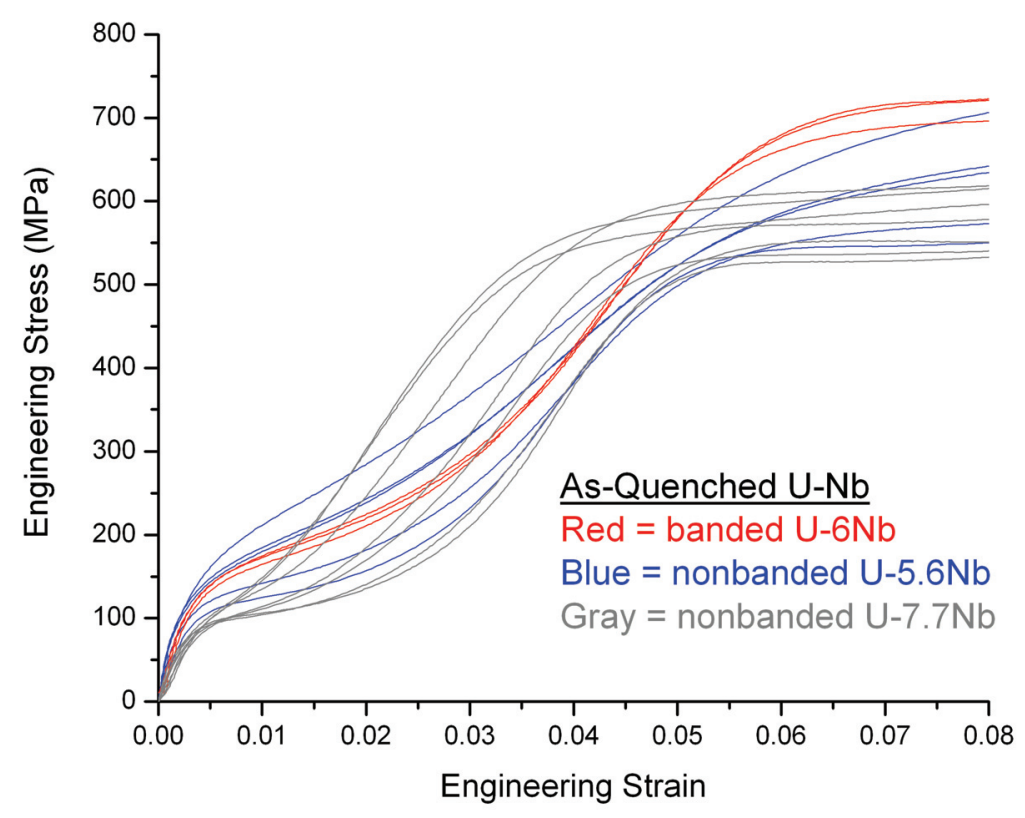

(b)

Figure 18. Tensile stress-strain curves for nonbanded $U-5.6 \mathrm{Nb}(03 \mathrm{~K}-425,5$ replicates) and nonbanded $U-7.7 \mathrm{Nb}(03 \mathrm{~K}-422$, 7 replicates). Curves from banded pictureframe $U-6 \mathrm{Nb}$ (3 replicates) are provided for comparison. All exhibit double-yielding behavior, highlighted in (b) where the strain axis is magnified with respect to (a). Key property values for these three alloys are listed in Table 6. 


\begin{tabular}{|c|c|c|c|c|c|c|c|c|}
\hline \multirow{2}{*}{$\begin{array}{c}\text { Alloy } \\
\text { (Plate ID) }\end{array}$} & \multirow[b]{2}{*}{ HV } & \multirow{2}{*}{$\begin{array}{c}1 \mathrm{YS} \\
(\mathrm{MPa})\end{array}$} & \multirow{2}{*}{$\begin{array}{c}2 \mathrm{YS} \\
(\mathrm{MPa})\end{array}$} & \multirow{2}{*}{$\begin{array}{c}\text { UTS } \\
\text { (MPa) }\end{array}$} & \multicolumn{2}{|c|}{$\begin{array}{l}\% \text { Plastic } \\
\text { Elongation }\end{array}$} & \multirow{2}{*}{$\begin{array}{c}\% \\
\text { Reduction } \\
\text { in Area }\end{array}$} & \multirow{2}{*}{$\begin{array}{c}\text { 1YS } \\
\text { Modulus } \\
\text { (GPa) }\end{array}$} \\
\hline & & & & & Uniform & Total & & \\
\hline $\begin{array}{l}\text { Banded } \\
\text { U-6Nb }\end{array}$ & $138 \pm 13$ & $138 \pm 3$ & $640 \pm 17$ & $861 \pm 8$ & $22.8 \pm 1.7$ & $25.5 \pm 2.2$ & $33.1 \pm 1.5$ & $50 \pm 3$ \\
\hline $\begin{array}{l}\text { Nonbanded } \\
\mathrm{U}-5.6 \mathrm{Nb} \\
(03 \mathrm{~K}-425)\end{array}$ & $147 \pm 8$ & $125 \pm 16$ & $545 \pm 47$ & $792 \pm 62$ & $20.1 \pm 1.1$ & $21.2 \pm 2.0$ & $28.0 \pm 10.2$ & $64 \pm 17$ \\
\hline $\begin{array}{l}\text { Nonbanded } \\
\text { U-7.7Nb } \\
(03 \mathrm{~K}-422)\end{array}$ & $115 \pm 2$ & $97 \pm 8$ & $509 \pm 19$ & $699 \pm 21$ & $26.2 \pm 3.3$ & $34.3 \pm 9.9$ & $42.1 \pm 14.0$ & $33 \pm 10$ \\
\hline
\end{tabular}

A study by Wood et al. of U-5.3 $\mathrm{Nb}$ ( $\alpha^{\prime \prime}$ microstructure) and $\mathrm{U}-6.8 \mathrm{Nb}$ ( $\gamma^{\circ}$ microstructure) offers useful parallels (Wood et al., 1983) to the present study. Their two alloys were produced by induction melting $18 \mathrm{~kg}$ heats and casting into rectangular graphite molds $(7 \times 5 \times 1.5 \mathrm{in}$.), using pre-alloyed (arc melted) starting material. Even though Wood et al. tested only 2-3 tensile specimens for each condition (as-quenched and aged), they observed tensile curves that were more reproducible than those in the present work. A higher homogenization temperature $\left(1,200^{\circ} \mathrm{C}-4\right.$ hours $)$, a somewhat larger degree of cross-rolling deformation (68\%) and a larger tensile size (rounds with 2-in. gage length and 0.25-in. gage diameter) in the Wood et al. study are factors that may have contributed to this higher reproducibility (though this is offset by their factor-of-three thicker mold that would be expected to result in slower cooling rates and longer microsegregation wavelengths). It should be noted that neither the point-to-point nor the through-thickness $\mathrm{Nb}$ homogeneity was reported, though top and bottom $\mathrm{Nb}$ levels in the ingot were reported and showed significant differences in the U-6.8 $\mathrm{Nb}$.

These property variations from otherwise identically solutionized-and-quenched specimens show different character in the two nonbanded plates of this study. The U-5.6Nb tended to have large variability in flow stress but modest variations in elongations, whereas $\mathrm{U}-7.7 \mathrm{Nb}$ has modest variability in flow stress but large variability in elongation. Both nonbanded plates had a large variability in percent reduction in area. Explanations that might account for these tensile variabilities include spatial (point-to-point) variations, at one or more length scales, in

1. the local $\mathrm{Nb}$ content; this is perhaps a bigger factor in $03 \mathrm{~K}-425$, given its higher standard deviation in center $50 \% \mathrm{Nb}$ content (see Table 1), and

2. the local inclusion density (regions of high inclusion density were occasionally seen by LOM in both alloys).

These as-quenched variations (whatever their origin) were small in magnitude relative to the aging response of this material, which was distinct, quantifiable, and suitable for input into an aging kinetics model (Hackenberg et al., 2007). 


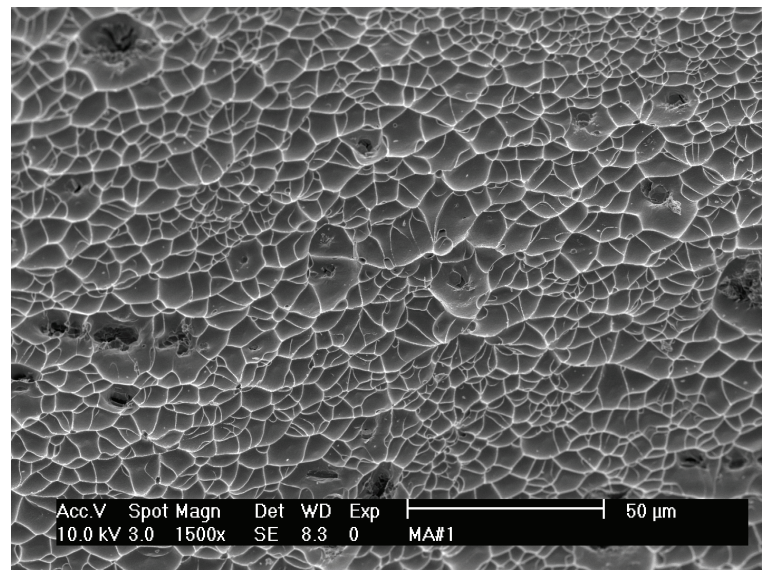

(a)

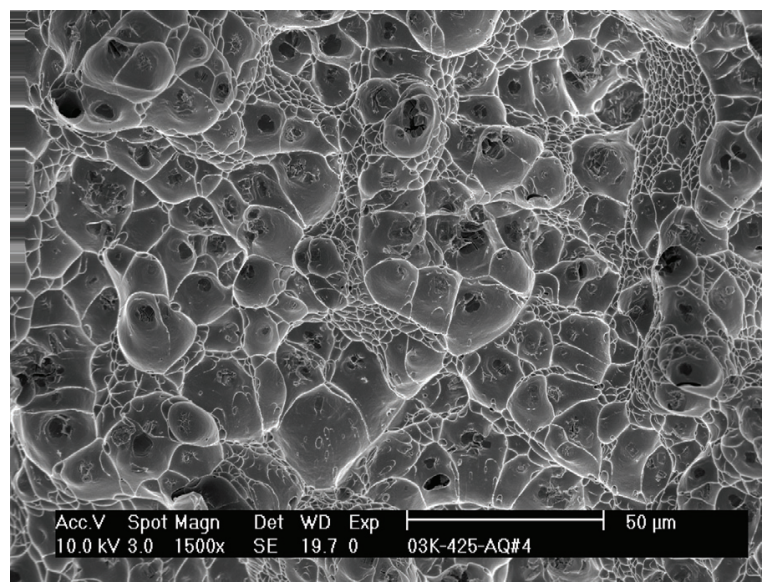

(c)

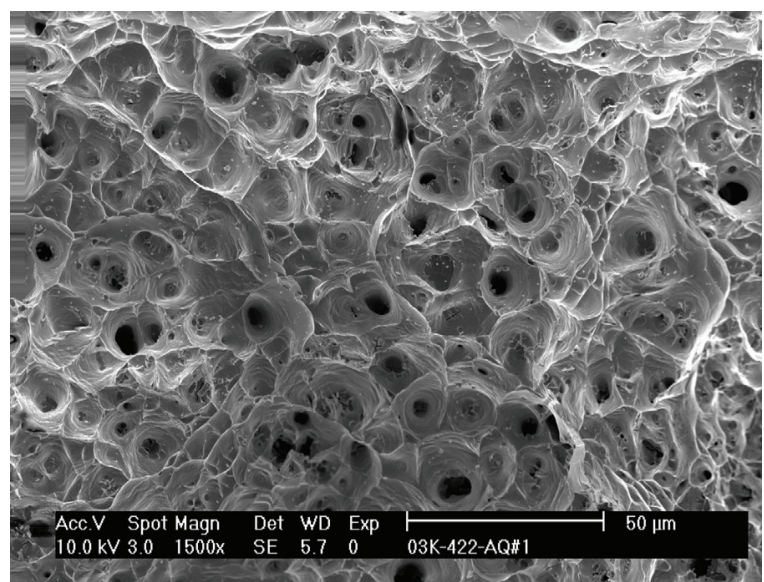

(e)

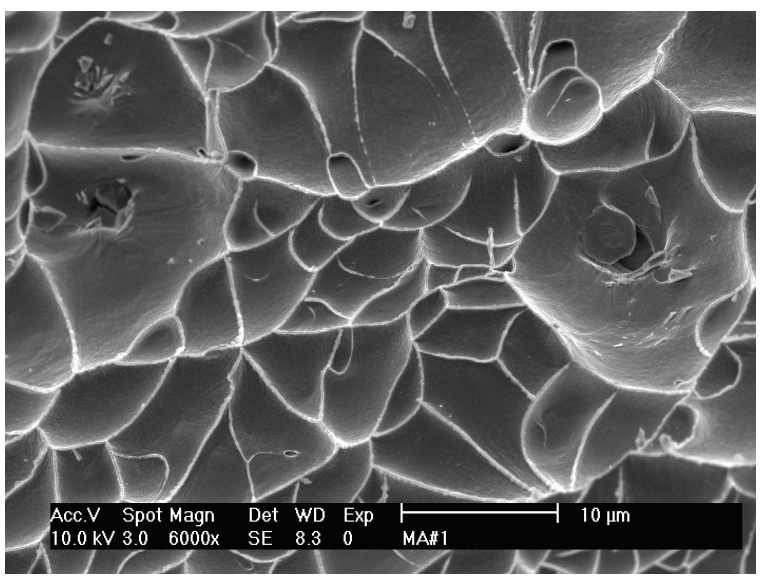

(b)

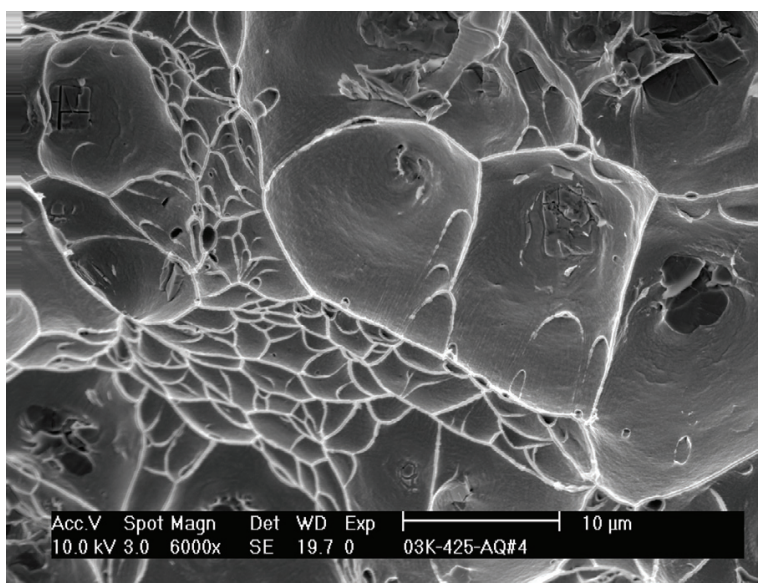

(d)

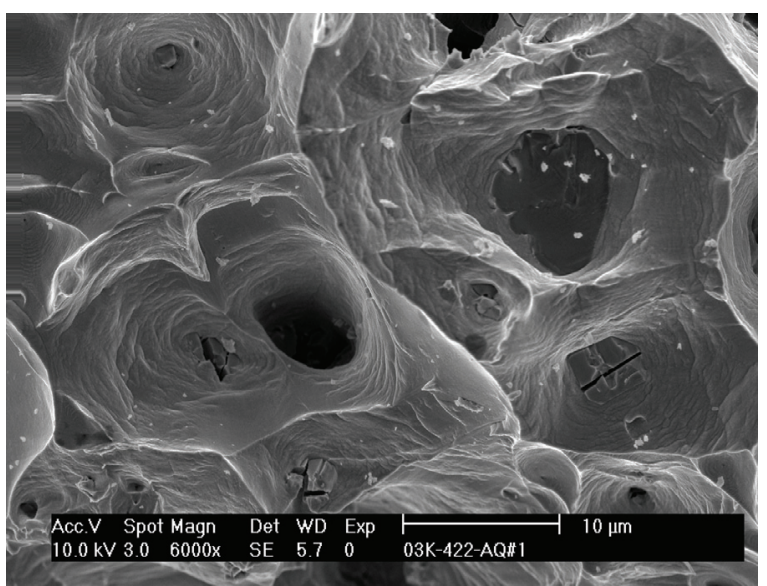

(f)

Figure 19. SEM fractographs from a subset of Fig. 18 as-quenched $U$-Nb tensile specimens: $(a, b)$ banded $U-6 \mathrm{Nb}(M A \# 1$, e(plastic, total $)=0.268, \% R A=31.4)$

(c, d) nonbanded $U-5.6 \mathrm{Nb}(A Q \# 4$, e(plastic, total $)=0.203, \% R A=24.1)$

$(e, f)$ nonbanded $U-7.7 \mathrm{Nb}(A Q \# 1$, e(plastic, total $)=0.339, \% R A=53.9)$ 


\section{CONCLUDING REMARKS}

The decision to use a thin unheated graphite mold for the initial casting of U-Nb plates did give the desired result of a cooling rate sufficient to reduce the coring (microsegregation) to a reasonable length scale of 40-50 microns, which facilitated realistic homogenization times. It also resulted in no top-to-bottom $\mathrm{Nb}$ variation, at least from the eight points measured. The unheated mold did, however, result in occasional areas in the casting with elongated voids and/or inclusion clusters occasionally seen by LOM and suspected in the occasional (aged) tensile specimens that seemed to fracture prematurely (though as-quenched fractography did not offer any further clues in this regard). What was remarkable was the significant amount of homogenization that took place in the $1,000^{\circ} \mathrm{C}-2$ hour prerolling anneal and the reheats during hot rolling that amounted to about an hour's total time at $850^{\circ} \mathrm{C}$. The postrolling homogenization of $1,000^{\circ} \mathrm{C}-6$ hours was sufficient to flatten out any remaining $\mathrm{Nb}$ variations, giving uniform $\mathrm{Nb}$ distributions over length scales of hundreds of microns. Impurity levels were within expected bounds and fairly low overall.

Although the macrosegregation of $\mathrm{Nb}$ on the $\sim 6 \mathrm{~mm}$ half-wavelength defining the plate cross-section was neither expected nor desired, the relative $\mathrm{Nb}$ homogeneity in the center $\sim 50 \%$ of the plate cross-section where specimens would be extracted for aging studies makes these plates effectively nonbanded for these purposes. The consistencies of the x-ray and dilatometry results of the homogenized, solutionized and quenched plate material with previous work give added confidence that this material is high quality and suitable for aging studies. Variability in the dilatation signals, tensile flow stress and tensile ductility was observed when replicate specimens were tested from a given plate, the origin of which is unclear. Nonetheless, it was observed that this as-quenched variability was small in magnitude relative to the tensile response after aging at temperatures up to $300^{\circ} \mathrm{C}$, which made this material suitable for its intended aging studies.

\section{REFERENCES}

Anagnostidis, M., M. Colombie, and H. Monti, "Phases Metastables dans les Alliages Uranium-Niobium," J. Nucl. Mater. 11, 67 (1964).

Eckelmeyer, K. H., "Diffusional Transformations, Strengthening Mechanisms and Mechanical Properties of Uranium Alloys," Sandia National Laboratory report SAND82-0524, Albuquerque, New Mexico (1982).

Eckelmeyer, K. H., A. D. Romig, Jr., and L. J. Weirick, "The Effect of Quench Rate on the Microstructure, Mechanical Properties, and Corrosion Behavior of U-6 Wt Pet Nb," Metall. Trans. A 15A, 1319 (1984).

Hackenberg, R. E., D. W. Brown, A. J. Clarke, L. B. Dauelsberg, R. D. Field, W. L. Hults, A. M. Kelly, M. F. Lopez, D. F. Teter, D. J. Thoma, T. J. Tucker, C. J. Vigil, and H. M. Volz, "U-Nb Aging Final Report," Los Alamos National Laboratory report LA-xxxxx, (to be issued 2007). 
Jackson, R. J., and D. V. Miley, "Tensile Properties of Gamma Quenched and Aged UraniumBase Niobium Alloys," Transactions ASM 61, 336 (1968).

Jackson, R. J., W. L. Johns, and A. E. Calabra, "Simplified Metallographic Techniques for Uranium Alloys and Other Metals," Rocky Flats Plant report RFP-862, Rocky Flats Plant, Golden, Colorado (1967).

Koike, J., M. E. Kassner, R. E. Tate, and R. S. Rosen, "The Nb-U (Niobium-Uranium) System," J. Phase Equilibria 19, 253 (1998).

Lao, K., and D. F. Teter, "Measurement of Hydrogen in U-6WT\%NB Using an Optimized Inert Gas Fusion Method," Corrosion/2004 Conference Paper 04562, NACE International, Houston, Texas (2004).

Larson, A. C., and R. B. Von Dreele, "General Structure Analysis System, Los Alamos National Laboratory report LA-UR-86-748 (1986).

Rhines, F. N., Phase Diagrams in Metallurgy, Addison-Wesley (1956).

Tangri, K., and D. K. Chaudhuri, "Metastable Phases in Uranium Alloys with High Solute Solubility in BCC $\gamma$ Phase. Part I - The System U-Nb," J. Nucl. Mater. 15, 278 (1965).

Vandermeer, R. A., J. C. Ogle, and W. B. Snyder, Jr., "Shape Memory Effects in a Uranium +14 at.\% Niobium Alloy”, Scripta Metall. 12, 243 (1978).

Volz, H. M., R. E. Hackenberg, A. M. Kelly, W. L. Hults, A. C. Lawson, R. D. Field, D. F. Teter, and D. J. Thoma, "X-Ray Diffraction Analyses of Aged U-Nb Alloys" accepted to J. Alloys and Compounds special issue for the conference Plutonium Futures 2006.

Wood, D. H., J. W. Dini, and H. R. Johnson, "Tensile testing of U/5.3 wt.\% Nb and U/6.8 wt.\% Nb alloys,” J. Nucl. Mater. 114 199-207 (1983). 
This report has been reproduced directly from the best available copy. It is available electronically on the Web (http://www.doe.gov/bridge).

Copies are available for sale to U.S. Department of Energy employees and contractors from:

Office of Scientific and Technical Information

P.O. Box 62

Oak Ridge, TN 37831

(865) 576-8401

Copies are available for sale to the public from: National Technical Information Service

U.S. Department of Commerce

5285 Port Royal Road

Springfield, VA 22161

(800) 553-6847 
- Los Alamos NATIONAL LABORATORY

EST.1943 